\title{
Targeting the AMPK pathway for the treatment of Type 2 diabetes
}

\author{
Benoit Viollet $^{1,2}$, Louise Lantier ${ }^{1,2}$, Jocelyne Devin-Leclerc ${ }^{1,2}$, Sophie Hebrard ${ }^{1,2}$, Chloe Amouyal $^{3}$, Remi Mounier ${ }^{1,2}$, Marc \\ Foretz $^{1,2}$, Fabrizio Andreelli ${ }^{1,2,3}$ \\ ${ }^{I}$ Institut Cochin, Universite Paris Descartes, CNRS (UMR 8104), Department Endocrinology, Metabolism and Cancer, Paris, \\ France, ${ }^{2}$ Inserm, U567, Paris, France, ${ }^{3}$ CHU Bichat Claude Bernard, Service de Diabetologie-Endocrinologie-Nutrition, AP- \\ HP, Paris, France
}

\section{TABLE OF CONTENTS}

1. Abstract

2. Introduction

3. Managing type 2 diabetes by targeting the AMPK pathway: an emerging concept

3.1. Lifestyle intervention strategies to prevent and control type 2 diabetes

3.2. Management of $\beta$-cell mass and function in type 2 diabetes

3.3. Management of cardiovascular diseases in type 2 diabetes

4. Structure and regulation of $A M P K$

5. Mimicking the beneficial effects of physical exercise

6. Mimicking the beneficial effects of calorie/dietary restriction

7. Role of AMPK in the control of glucose homeostasis

8. Role of AMPK in the control of lipid metabolism

9. Management of fatty liver disease by AMPK activation

10. Role of $A M P K$ in the regulation of $\beta$-cell function

11. Management of cardiovascular diseases by AMPK activation

12. Conclusion and medical perspectives

13. Acknowledgments

14. References

\section{ABSTRACT}

Type 2 diabetes is one of the fastest growing public health problems worldwide, resulting from both genetic factors and inadequate adaptation to environmental changes. It is characterized by abnormal glucose and lipid metabolism due in part to resistance to the actions of insulin in skeletal muscle, liver and fat. AMP-activated protein kinase (AMPK), a phylogenetically conserved serine/threonine protein kinase, acts as an integrator of regulatory signals monitoring systemic and cellular energy status. The growing realization that AMPK regulates the coordination of anabolic and catabolic metabolic processes represents an attractive concept for type 2 diabetes therapy. Recent findings showing that pharmacological activation of AMPK improves blood glucose homeostasis, lipid profile and blood pressure in insulin-resistant rodents suggest that this kinase could be a novel therapeutic target in the treatment of type 2 diabetes. Consistent with these results, physical exercise and major classes of antidiabetic drugs have recently been reported to activate AMPK. In the present review, we update these topics and discuss the concept of targeting the AMPK pathway for the treatment of type 2 diabetes.

\section{INTRODUCTION}

The increased prevalence of obesity and type 2 diabetes, with the attendant increase in morbidity and mortality, pose a substantial therapeutic challenge. Type 2 diabetes is a complex polygenic disease with a strong genetic component, as indicated by the high prevalence in certain ethnic groups and by studies of identical twins. Nevertheless, the rapid increase in the prevalence of obesity-associated disease conditions, including type 2 diabetes, in worldwide populations suggests the contribution of environmental factors. A widely accepted explanation lays on the frequent consumption of processed foods with a high-calorie content and the reduction in physical exercise due to sedentary lifestyle in modern urban environment. Disruption of energy balance has led to an increased prevalence of these conditions (1). Type 2 diabetes is characterized by altered lipid and glucose metabolism (fasting or postprandial hyperglycemia, dyslipidemia) as a consequence of combined insulin resistance in skeletal muscle, liver and adipose tissue and relative defects of insulin secretion by $\beta$-cells that may arise due to an imbalance between energy intake and expenditure (2). Insulin resistance occurs when a normal 
dose of hormone is unable to elicit its metabolic responses. Insulin is the primary anabolic hormone that stimulates uptake and storage of fuel substrates, while inhibiting substrate production in peripheral tissues. It lowers blood glucose levels by facilitating glucose uptake, mainly into skeletal muscle and fat tissue, and by inhibiting endogenous glucose production in the liver. Peripheral insulin resistance is associated with lipid partitioning in specific compartments, i.e. muscle and liver, more than with obesity per se. Usually, after an asymptomatic period of insulin resistance, hyperglycemia appears when pancreatic $\beta$-cells fail to secrete sufficient amounts of insulin to meet the metabolic demand. In the natural history of type 2 diabetes, pancreatic $\beta$-cells initially compensate for insulin resistance by hypersecretion of insulin, but with time, progressive $\beta$-cell failure leads to insulin deficiency, and hyperglycemia ensues. Progression in diabetes leads to the development of chronic complications such as blindness, kidney failure, neuropathy, cardiovascular diseases and amputations. Thus novel ways to prevent and treat type 2 diabetes are urgently needed.

Non-pharmacological approaches including diet modification, weight control, regular exercise and patient education are used as first-line therapy for the management of type 2 diabetes and remain important for optimization of metabolic control. When lifestyle modification fails to achieve or sustain adequate glycemic control, insulin or oral anti-diabetic agents are typically used to manage the disease. Treatment options with oral agents are quite diverse, including metformin (Glucophage ${ }^{\circledR}$ ) (inhibition of hepatic glucose production), thiazolidinediones (TZDs) (insulin sensitizers), $\alpha$-glucosidase inhibitors (inhibition of gut glucose absorption) and sulphonylureas ( $\beta$-cell secretagogues). Several new drugs with glucose-lowering efficacy offering certain advantages have recently become available, such as injectable glucagon-like peptide-1 (GLP1) receptor agonists and oral dipeptidyl peptidase-IV (DPPIV) inhibitors. Both of them are promising not only to normalize fasting and postprandial glucose levels but also to improve $\beta$-cell functioning and mass by stimulating neogenesis. Indeed, $\beta$-cell plasticity enables these cells to adapt their number and volume ( $\beta$-cell mass) and their function to the increased secretory demand linked to insulin resistance. The currently available classes of oral agents differ in mechanism and duration of action, the degree to which they lower blood glucose and their side-effect profile. Although in recent years the emphasis on initial therapy has been shifting from insulin secretagogues to insulin sensitizers, their mechanisms of action are still incompletely understood. Exciting recent developments have shown that AMP-activated protein kinase (AMPK), a phylogenetically conserved serine/threonine protein kinase, is one of the probable target of major antidiabetic drugs, metformin and TZDs, and of insulin sensitizing adipokines (e.g., adiponectin). Evidence accumulated over the past few years indicates that AMPK acts as an integrator of regulatory signals monitoring systemic and cellular energy status, thus providing powerful validation of the concept of targeting the AMPK pathway for the treatment of type 2 diabetes.

\section{MANAGING TYPE 2 DIABETES BY TARGETING THE AMPK PATHWAY: AN EMERGING CONCEPT}

\subsection{Lifestyle intervention strategies to prevent and control type 2 diabetes}

During the past two decades, type 2 diabetes has reached pandemic proportions in association with rising levels of obesity and inactivity. Although physical activity is known to produce multiple health benefits, many people are considered to be relatively physically inactive. Current guidelines recommend practical, regular and moderate regimens of physical activity. The multiple metabolic adaptations that occur in response to physical activity can improve glycemic control for individuals with type 2 diabetes or delay the onset of the disease. This is supported by observational studies and clinical trials of diet, drugs or exercise, in persons at high risk for type 2 diabetes (3-5). The Diabetes Prevention Program (DPP) Research Group conducted a large, randomized clinical trial involving adults in the United States who were at high risk for the development this disease (5). Eligible participants were randomly assigned to one of three interventions: standard lifestyle recommendations plus metformin at a dose of 850 $\mathrm{mg}$ twice daily, standard lifestyle recommendations plus placebo twice daily, or an intensive program of lifestyle modification (low-calorie, low-fat diet and physical activity of moderate intensity). The incidence of diabetes was reduced by $58 \%$ with the lifestyle intervention and by $31 \%$ with metformin, as compared with placebo after 3 years of follow-up. These effects were similar in men and women. In this study, the lifestyle intervention was particularly effective (and more than metformin treatment), with one case of diabetes prevented per seven persons treated for three years.

In addition to impacting development of type 2 diabetes, regular physical activity participation is associated with numerous health benefits for the individual with diabetes. Physical activity appears to have an independent and beneficial effect on insulin action, glycemic control and metabolic abnormalities associated this disease (6). Regular physical activity leads to a number of beneficial physiological changes that favourably affect muscle and liver insulin sensitivity, muscle glucose uptake and utilization and overall glycemic control (7). In addition, performed activity can improve lipid profile, decrease body weight and percentage of body fat, lower blood pressure, positively affect thromboembolic state and thus reduce overall cardiovascular disease risk $(8,9)$. These beneficial effects are partly explained by AMPK activation during physical activity not only in skeletal muscle but also in liver and adipose tissue (10). Indeed, in type 2 diabetes patients, improvement in glycemic control during physical activity is linked to enhanced glucose transport in skeletal muscle and reduction in hepatic glucose production (11). Interestingly, these effects are insulin-independent. This probably explains that, despite whole-body insulin resistance, AMPK can be fully activated by physical training in type 2 diabetes patients as compared to healthy controls (12). In addition to this acute metabolic effect on glucose disposal, repeated physical activity improves insulin action in skeletal muscle from obese and insulin- 
resistant individuals (13). This improvement parallels an increase in the oxidative capacity of skeletal muscle by upregulating lipid oxidation and the expression of proteins involved in mitochondrial biogenesis. Both of these mechanisms are linked to AMPK activation that seems to be a crucial key for metabolic adaptation to physical activity (see below). The use of AMPK agonists could be a new strategy to increase endurance without exercise in physically inactive type 2 diabetes patients.

\subsection{Management of $\beta$-cell mass and function in type 2 diabetes}

Clinical studies demonstrated that TZDs improve $\beta$ cell function for a long time both as monotherapy and in combination with metformin or sulfonylurea (14). They may also improve insulin processing, as demonstrated by a reduction in the proinsulin/total immunoreactive insulin ratio, (an indicator of $\beta$-cell dysfunction) whereas sulfonylureas did not (15). More importantly, TZDs can prevent or delay type 2 diabetes in patients with impaired fasting glucose. This has been clearly demonstrated in different clinical studies, such as TRIPOD (Troglitazone in Prevention of Diabetes) (16), PIPOD (Pioglitazone in Prevention of Diabetes) (17) in women with prior gestational diabetes mellitus, DPP (5) and DREAM (Diabetes Reduction Assessment with Ramipril and Rosiglitazone Medication) (18). In consequence, these clinical trials support the idea that early detection and proper preventive measures, including TZDs treatment, can prevent the progression of high-risk patients from developing type 2 diabetes. Interestingly, metabolic and insulin-sensitizing effects of TZDs have been shown to be in part mediated through adiponectin-dependent activation of AMPK since activation of AMPK by rosiglitazone treatment is diminished in adiponectin KO mice (19). TZDs can markedly enhance the expression and secretion of adiponectin in humans and rodents in vitro and in vivo, through the activation of its promoter and also antagonize the suppressive effect of TNF- $\alpha$ on the production of adiponectin (20).

\subsection{Management of cardiovascular diseases in type 2 diabetes}

Cardiovascular disease (CVD) is the main cause of morbidity/mortality in diabetes. As suggested by the results of the clinical trial ACCORD (Action to Control Cardiovascular Risk in Diabetes), there is no evidence that normoglycemia can, by itself, lower the CVD in type 2 diabetic patients (21). Thus, it is necessary to develop new strategies to reduce CVD in this population. Metformin has cardioprotective effects on lipids, thrombosis and blood flow. It was reported that metformin was associated with a reduction by $32 \%$ in any diabetes related endpoint and in myocardial infarction by $39 \%$ (22). The figures for macrovascular complications compare favourably for those described for other cardioprotective agents such as angiotensin converting enzyme (ACE) inhibitors and statins. The beneficial effect of metformin on CVD is independent of changes in insulin resistance or glucose control suggesting a direct effect on vessels. Studies in vitro or in type 2 diabetes rodents models clearly demonstrated that metformin normalizes endothelial function (23). Similarly, adiponectin has protective effect on endothelial functions and CVD and type 2 diabetes mellitus are associated with low plasma concentration of adiponectin (24). In isolated rat hearts, adiponectin protects from myocardial contractile dysfunction and limits infarct size in following ischaemia and reperfusion by a mechanism involving activation of AMPK and production of NO (25). In humans, clinical trials concerning use of recombinant adiponectin during myocardial infarction are not available. Nevertheless, the increase of blood adiponectin levels to normal range after a cardiovascular event could be a new therapeutic target. To this aim, the association of drugs classically used for the prevention of recurrence of CVD and some dietary modifications could be useful to restore adiponectin levels in the normal range. This has been described recently in a double-blind, placebo-controlled, parallel trial where 44 patients who survived myocardial infarction and received statin therapy for at least 6 months were randomised to receive either $3 \mathrm{x}$ $85 \mathrm{mg}$ /day of chokeberry flavonoid extract or placebo for a period of 6 weeks (26). A significant increase in adiponectin levels and also a reduction in inflammatory markers were found when flavonoid extract was used. These beneficial effects, regardless of statins, are potentially interesting for secondary prevention of ischaemic heart disease.

\section{STRUCTURE AND REGULATION OF AMPK}

AMP-activated protein kinase (AMPK) plays an important role in the regulation of cellular and whole-body energy homeostasis. AMPK has been described as a "metabolic master switch" that mediates the cellular adaptation to nutritional and environmental variations depleting intracellular ATP levels, including heat shock, hypoxia, starvation or prolonged exercise. Regardless, the result of AMPK activation is the inhibition of energyconsuming biosynthetic pathways (such as fatty acid synthesis in liver and adipocytes, cholesterol synthesis in liver, protein synthesis in liver and muscle and insulin secretion from $\beta$-cell) and the activation of ATP-producing catabolic pathways (such as fatty acid uptake and oxidation in multiple tissue, glycolysis in heart and mitochondrial biogenesis in muscle). AMPK can also modulate the transcription of specific genes involved in energy metabolism, thereby exerting long-term metabolic control.

AMPK is composed of three different subunits $\alpha$, $\beta$ and $\gamma$. Homologues of these subunits have been identified in mammals, Drosophila, worm, yeast, plants and primitive protozoon, with a high degree of conservation, suggesting the important role of AMPK in regulation of metabolic homeostasis. In mammals, the heterotrimeric complexes combine catalytic $\alpha$ subunit ( $\alpha 1$ or $\alpha 2)$, with $\beta$ ( $\beta 1$ or $\beta 2$ ) and $\gamma(\gamma 1, \gamma 2$ or $\gamma 3)$ regulatory subunits encoded by separate genes yielding to 12 heterotrimeric combinations (Figure 1). In addition, the $\gamma 2$ and $\gamma 3$ genes also give rise to short and long splice variants adding to the diversity. Differences in level expression and tissue distribution of the three subunits types were also described. The catalytic $\alpha 1$ subunit is strongly expressed in the kidney, the lung and the adipose tissue, whereas catalytic $\alpha 2$ subunit is 


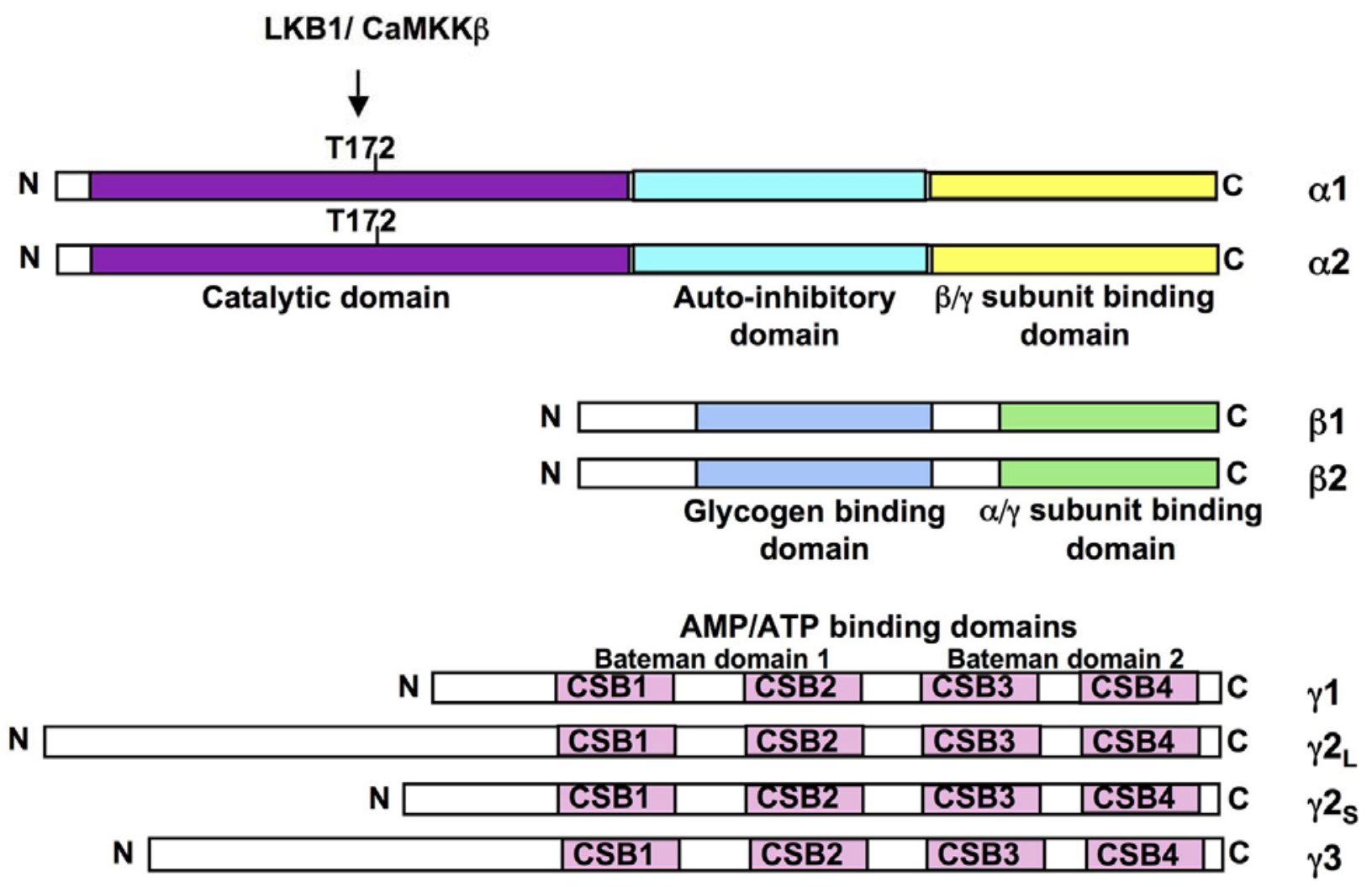

Figure 1. Structure of AMPK. The mammalian AMPK $\alpha(\alpha 1$ and $\alpha 2)$, AMPK $\beta$ ( $\beta 1$ and $\beta 2)$ and AMPK $\gamma(\gamma 1, \gamma 2$ short form, $\gamma 2$ long form and $\gamma 3$ ) subunits are shown. The $\alpha$-subunits contains the Thr172 residue that must be phosphorylated (P) by upstram kinases for activity and an autoinhibitory sequence domain that inhibits the activity of the kinase domain. The C-terminal domain is required for binding the $\beta$ - and $\gamma$-subunits. The $\beta$-subunits contains central glycogen-binding domains and C-terminal domain that is required for binding the $\alpha$ - and $\gamma$-subunits. The three $\gamma$-subunit isoforms have variable N-terminal domains and four conserved cystathionine beta-synthase motifs (CBS1-4). The CBS motifs act in pairs to form two Bateman domains that bind AMP or ATP.

predominantly found in heart and skeletal muscles. The regulatory $\beta 1$ subunit is preferentially expressed in the liver and $\beta 2$ in the skeletal muscle. The regulatory $\gamma 1$ and $\gamma 2$ subunits have broad tissue distribution whereas $\gamma 3$ seems highly specific to glycolytic skeletal muscle. Moreover, despite the possible multiple combinations of the different subunits, only three are found in human skeletal muscle $(\alpha 2 \beta 2 \gamma 1 ; \alpha 2 \beta 2 \gamma 3$ and $\alpha 1 \beta 2 \gamma 1)$ with different levels of expression and activation during exercise $(27,28)$. The $\alpha$ subunit contains a serine/threonine protein kinase catalytic domain in the $\mathrm{N}$-terminal part, typical of the protein kinase superfamily (29). The catalytic domain has a site of phosphorylation at threonine residue Thr172 within the activation loop (T-loop) which is the key site for AMPK activation by upstream kinases $(30,31)$. In the extreme $\mathrm{C}$ terminus part, a region of $\sim 150$ amino acid residues is required for association with $\beta$ and $\gamma$ subunits, whereas the central part seems to have an inhibitory function $(32,33)$. Moreover, localization of $\alpha 2$-containing complexes both in the nucleus and the cytoplasm implies a direct control of genes expression via phosphorylation of transcription factors (34). The $\beta$ subunit appears to stabilize the interaction between $\alpha$ and $\gamma$ subunits through its binding domain in the C-terminal part $(35,36)$. In addition, the presence of a glycogen-binding domain in the N-terminal part corroborates the fact that AMPK binds glycogen granules and regulates glycogen metabolism $(37,38)$. The high variable $\gamma$ subunits are characterized by the presence of four cystathionine- $\beta$ synthase (CBS) domains organized in tandem pairs to generate two binding sites for AMP or ATP, bound in a mutually exclusive manner, called Bateman domains (39). Glycogen storage disorders and a related hereditary heart disease have been described consecutively to mutations in these domains for the $\gamma 3$ and $\gamma 2$ genes, respectively $(40,41)$. Recently, in addition to the yeast homologue Snf1 (42) and mammalian glycogenbinding site of $\beta 1$ subunit (43), crystal structure of a trimeric complex containing the C-terminal domains of $\alpha 1$ and $\beta 2$ with full-length $\gamma 1$ was resolved, in presence of AMP or Mg-ATP. The results confirm the binding of either AMP or ATP on two known sites of the $\gamma$ subunit and reveal a third site with tightly bound AMP. Under physiological conditions, AMPK interacts predominantly with Mg-ATP to form inactive complexes which are more abundant than complexes with AMP. These studies also suggest that binding of phosphorylated $\alpha$ and/or $\beta$ subunit 


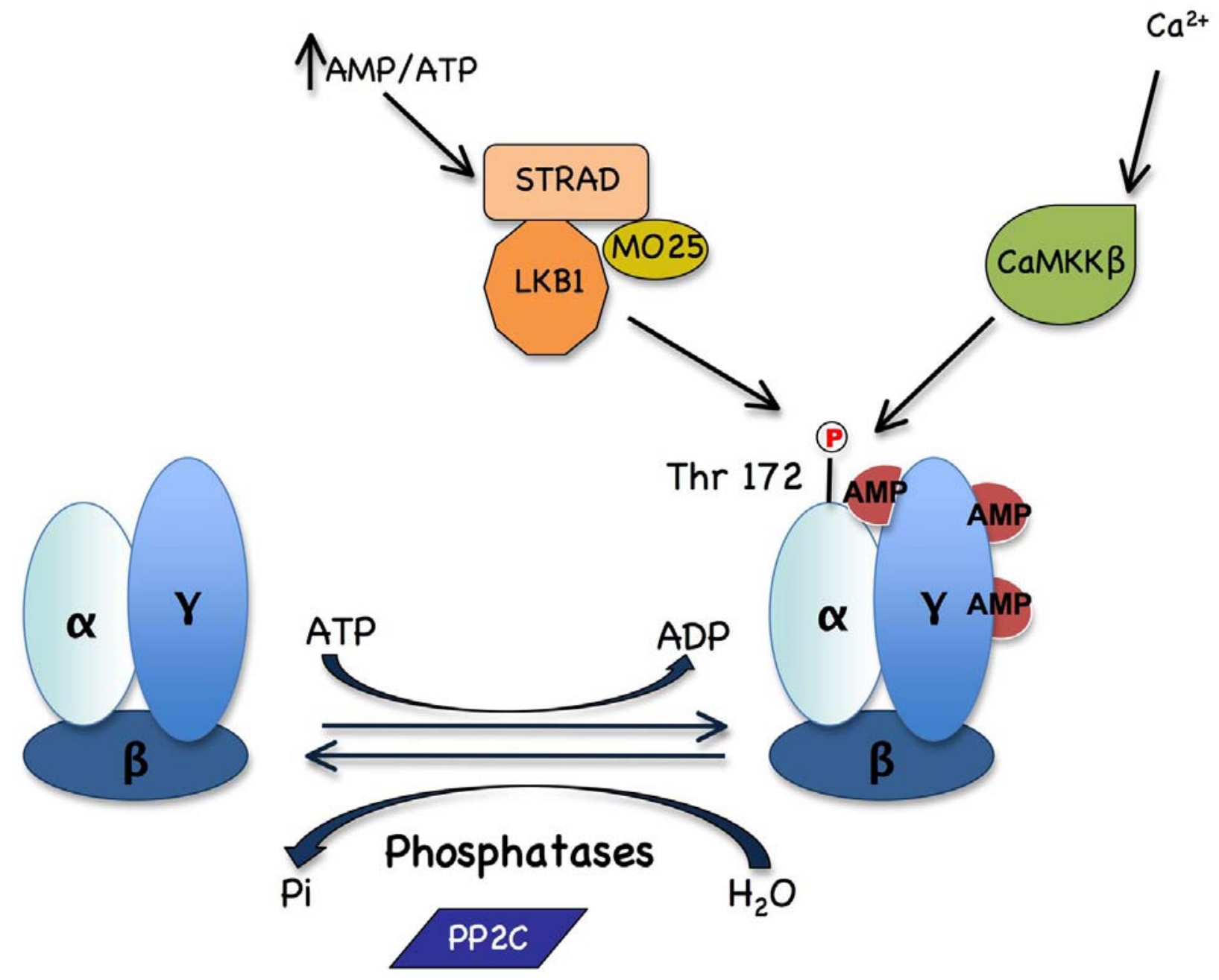

Figure 2. Regulation of AMPK activation. AMPK is activated by phosphorylation of Thr 172 catalysed by LKB1:STRAD:MO25 complex in response to increase in the AMP/ATP ratio and by CaMKK $\beta$ in response to elevated $\mathrm{Ca}^{2+}$ levels. Thr172 is dephosphorylated by $\mathrm{PP} 2 \mathrm{C}$ protein phosphatase switching active AMPK to the inactive form.

(s) would be possible in the presence of AMP but not when ATP is bound to the $\gamma$ subunit (44). In addition to the multiple combinations of the three different subunits in the heterotrimeric complex, as well as their tissue-specific expression, the various regulations (i.e. phosphorylation, binding of AMP/ATP and glycogen) and subcellular localization may constitute a very fine and specific regulation of the metabolic tracts by AMPK.

Regulation of AMPK activity involves both direct allosteric activation by AMP and reversible phosphorylation of AMPK $\alpha$ subunit on Thr172 by upstream kinases (Figure 2). The combination of the allosteric and phosphorylation effects causes $>1000$-fold increase in kinase activity (45) allowing to respond to small changes in cellular energy status in a highly sensitive manner. Under conditions of high cellular energy demands, intracellular ATP is reduced, AMP levels rise and the AMP/ATP ratio forms a very sensitive indicator of cellular energy status (46). Binding of AMP to the regulatory $\gamma$ - subunit of AMPK promotes allosteric activation, phosphorylation of Thr172 by upstream kinases and inhibition of dephosphorylation of Thr172 by protein phosphatases. There are at least two protein kinases capable of phosphorylating Thr172 in vivo, LKB1 (47-49) and $\mathrm{Ca} 2+$ /calmodulin-dependent kinase kinase (50-52), especially the $\beta$ isoform (CaMKK $\beta$ ). LKB1, originally identified as a tumour suppressor, exists as a complex with two accessory subunits, STRAD and MO25. The LKB1 complex is supposed to be constitutively active and to promote activation by the AMP-dependent pathway (49) but recent studies indicate that cytosolic localization and activity of LKB1 can be governed by LKB1 acetylation status in the liver (53). An alternate pathway for AMPK activation involves CaMKK $\beta$ which responds to changes in cytoplasmic $\mathrm{Ca} 2+$ levels, indicating that AMPK may be activated in the absence of increase levels of AMP (50-52). Phosphorylation and activation of AMPK can be reversed by protein phosphatases. Binding of AMP to AMPK induces a conformational change in the kinase domain that 
protects AMPK from dephosphorylation of Thr-172 (54), probably catalysed by a form of protein phosphatase-2C (55).

\section{MIMICKING THE BENEFICIAL EFFECTS OF PHYSICAL EXERCISE}

Although appropriate diet and exercise regimes should therefore be the first choice of treatment and prevention of type 2 diabetes, there are patient groups for whom such regimes are not appropriate for other medical reasons, or where compliance is difficult because of social factors or poor motivation. In these cases, drugs acting on the signaling pathways that induce the favourable changes in whole body metabolism are attractive candidates for treatment and prevention. It is now well established that muscle contraction is a prototypical AMPK activator (56). It has been suggested that AMPK activation may recapitulate some of the exercise-induced adaptations and is likely to mediate beneficial effects of exercise on insulin sensitivity and glucose transport in skeletal muscle (57). Activation of AMPK with the pharmacological compound AICAR (5-Aminoimidazole-4-carboxamide-1- $\beta$-Dribonucleoside, metabolized to ZMP which is an analog of AMP) increases running endurance in untrained mice suggesting that AMPK agonists are exercise mimetics (58). Furthermore, AICAR upregulates genes linked to oxidative metabolism, angiogenesis and glucose sparing (58). Thus, it is expected that part of the effect of physical activity in preventing the development of diseases related to a sedentary lifestyle is due to activation of AMPK. However, although the activation of AMPK in skeletal muscle can lead to the stimulation of glucose transport, contractionstimulated glucose transport is normal or partly affected in transgenic mouse models overexpressing dominant negative form of $\mathrm{AMPK} \alpha 2$, in skeletal muscle and in whole body AMPK $\alpha 1$ and AMPK $\alpha 2$ knock-out (KO) mice (59-62). These results suggest that muscle contraction leads to the activation of multiple redundant signaling pathways and that inhibition of only one is not sufficient to alter contraction-induced glucose transport. Conversely, activation of AMPK with agents that elicit or mimic the effects of contraction (changes in AMP:ATP ratio, intracellular $\mathrm{Ca}^{2+}$ levels and reactive oxygen species) is responsible for increase in muscle glucose transport. Studies with AMPK activators in animal models of type 2 diabetes have provided promising results. The first evidence came from in vivo treatment with the pharmacological compound AICAR of various animal models of insulin resistance, causing improvement in most, if not all, the metabolic disturbances of these animals (6367). Interestingly, long-term AICAR administration prevents the development of hyperglycemia in Zucker diabetic fatty (ZDF) rats, improves peripheral insulin sensitivity in skeletal muscle and delays $\beta$-cell dysfunction associated with type 2 diabetes (66). In addition, ablation of AMPK $\alpha 2$ specifically in skeletal muscle, exacerbates the development of insulin resistance and glucose intolerance caused by high-fat feeding (68). Finally, it was reported that the insulin sensitizing effects of AICAR were diminished by inhibition of AMPK in $\mathrm{C} 2 \mathrm{C} 12$ myotubes (69). Repetitive pharmacological activation of AMPK in vivo results in expression of specific muscle proteins mimicking some of the effects of exercise training such as increased glucose uptake and mitochondrial biogenesis (Figure 3). In rodent, AICAR or chronic intake of the creatine analogue $\beta$-guanidinopropionic acid ( $\beta$-GPA) increases the expression of genes encoding glucose transporter GLUT4, hexokinase II and markers of mitochondrial biogenesis (70-73). A recent report reveals that peroxisome proliferator-activated receptor- $\gamma$ coactivator-1 $\alpha$ (PGC-1 $\alpha$ ) expression is required for AMPK-dependent activation of gene expression, including PGC-1 $\alpha$ itself, GLUT4 and mitochondrial genes (74). Interestingly, these gene expression effects are abolished in AMPK $\alpha 2 \mathrm{KO}$ mice and transgenic mice overexpressing a kinase-dead AMPK $\alpha 2$ mutant in skeletal muscle (mAMPK-KD mice) $(75,76)$.

Recent studies support the critical role of AMPK in the metabolic adaptation of skeletal muscle to exercise training. Over-expression of an active AMPK $\gamma 1 \mathrm{R} 70 \mathrm{Q}$ mutant in skeletal muscle significantly rises the relative proportion of type IIa/x fibers, the expression of PGC- $1 \alpha$ and the activity of mitochondrial markers in sedentary transgenic animals compared to their sedentary controls, without any further increase with exercise training (77). Moreover, AMPK $\alpha 2 \mathrm{KO}$ mice have a disturbed muscle energy balance during exercise, as indicated by a reduced ATP content (76). Physical training also increases circulating adiponectin and mRNA expression of its receptors in muscle, which may mediate the improvement of insulin resistance in response to exercise by activation of AMPK (78). Interestingly, metformin treatment of subjects with type 2 diabetes significantly increases AMPK activity in skeletal muscle and this stimulation is accompanied by enhanced peripheral glucose disposal $(79,80)$. Metformin is also able to restore glucose uptake stimulation in insulinresistant cardiomyocytes, suggesting that AMPK activation could be a potential therapeutic approach to treat insulin resistance in diabetic hearts (81). Finally, activation of AMPK in response to physical exercise is also observed in extra-muscular tissues such as liver and adipose tissue and might account for additional metabolic benefits (10).

\section{MIMICKING THE BENEFICIAL EFFECTS OF CALORIE / DIETARY RESTRICTION}

Calorie intake is an important determinant of health. Excessive calorie intake and subsequent abdominal obesity increase the risk of developing chronic disease such as type 2 diabetes, cardiovascular complications and premature mortality. In overweight and obese humans, calorie restriction (CR) with adequate nutrition improves glucose tolerance and insulin action and reduces mortality for type 2 diabetes and cardiovascular diseases (82-85). Even if calorie restriction produces a metabolic profile desirable for treating type 2 diabetes, it is unlikely that such restriction will be widely adopted because of the difficulty in maintaining long-term low calorie intake in modern society. There is an increased interest in developing pharmacological agents acting as "calorie-restriction" mimetics. Such agents could provide the beneficial metabolic, hormonal and physiological effects of calorie 


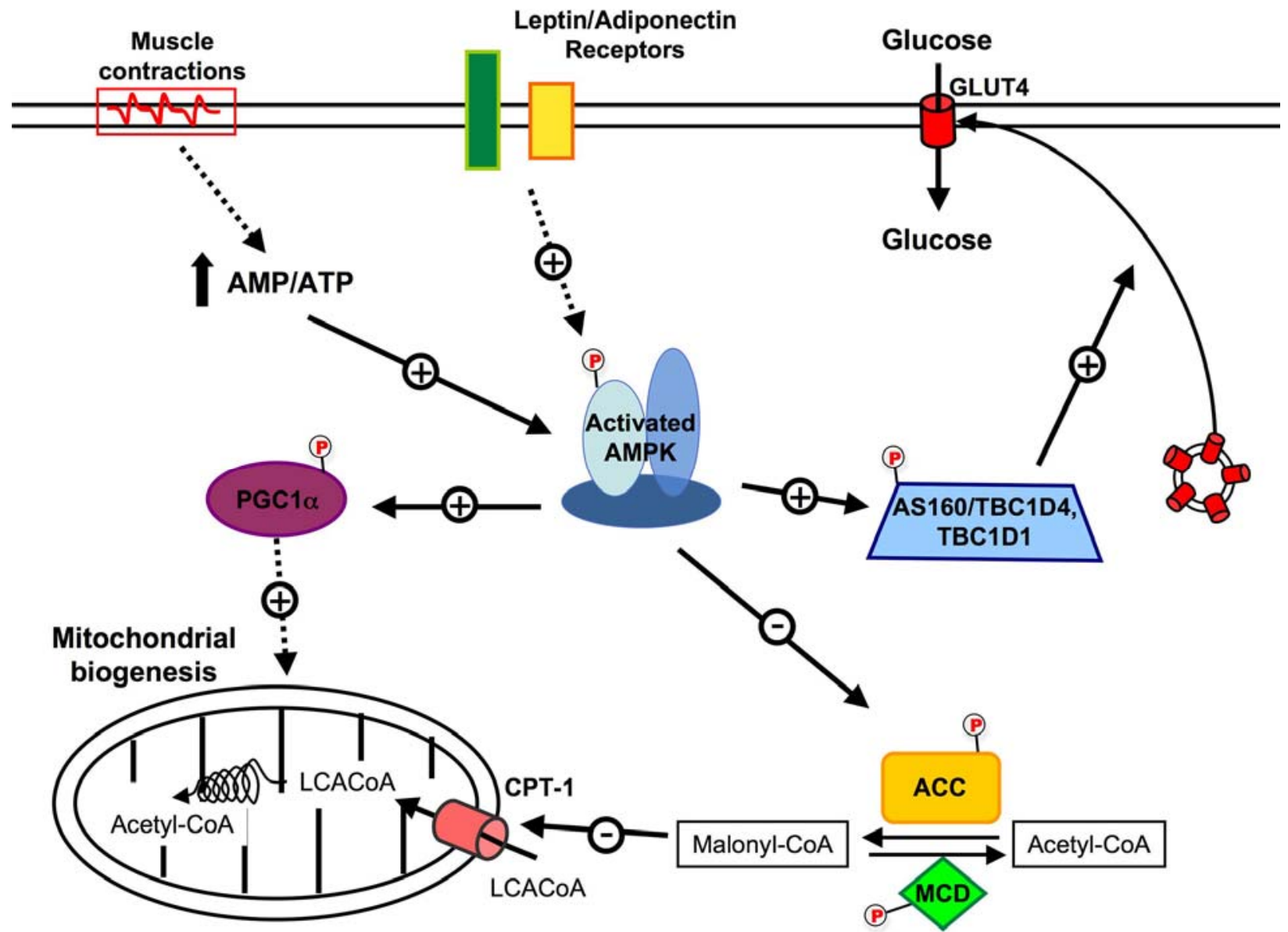

Figure 3. AMPK and the regulation of hepatic metabolism. Activation of AMPK leads to the inhibition of cholesterol synthesis by the phopshorylation of HMG-CoA reductase. By inhibiting ACC and activating MCD, AMPK increases fatty acid oxidation via the regulation of malonyl CoA levels, which is both a critical precursor for biosynthesis of fatty acids and a potent inhibitor of CPT-1, the shuttle that controls the transfer of LCACoA into the mitochondria. AMPK inhibits hepatic glucose production via the phosphorylation of TORC2 and inhibition gene expression for key gluconeogenic enzymes, G6Pase and PEPCK, and for the transcriptional co-activator PGC-1 $\alpha$. ACC, acetyl-CoA carboxylase; AMPK, AMP-activated protein kinase; CPT1- $\alpha$, carnitine palmitoyl transferase-1; G6Pase, glucose-6-phosphatase; LCACoA, Long Chain acyl CoAs; MCD, malonyl-CoA decarboxylase; PEPCK, phosphoenolpyruvate carboxykinase; PGC1 $\alpha$, PPAR $\gamma$ co-activator $1 \alpha$; TORC2, transducer of regulated CREB activity 2.

restriction without altering dietary intake or experiencing any potential adverse consequences of excessive restriction. The plant-derived polyphenolic compounds, such as resveratrol (RSV) present in grapes, peanuts and several other plants, recently held great attention for their role in mimicking the effects of calorie restriction. This was evidenced by the findings that RSV can delay the aging process in lower eukaryotes (86). In rodents, RSV prevents the deleterious effects of excess calorie intake on insulin resistance and metabolic disorders (87-91). RSV acts as a potent activator of the NAD (+)-dependent deacetylases sirtuins including SIRT1, one of the seven mammalian sirtuin genes. SIRT1 has been suggested to prime the organism for metabolic adaptation to insulin resistance, increasing hepatic insulin sensitivity and decreasing wholebody energy requirements $(91,92)$. It is also involved in insulin secretion $(93,94)$ and lipid mobilization (95).
Interestingly, the polyphenols RSV and epigallocatechin-3gallate (EGCG) were recently identified as potent activators for AMPK in vitro and in vivo $(88,96,97)$. Furthermore, it has been demonstrated that SIRT1 functions as an upstream regulator of the LKB1/AMPK signaling axis in response to RSV activation in hepatocytes (98). SIRT1 promotes LKB1-dependent AMPK stimulation through the direct deacetylation and activation of LKB1 (53). It should be noted that the regulation of LKB1/AMPK signaling by SIRT1 is probably tissue-specific as resveratrol-stimulated AMPK activation is independent of SIRT1 in neurons (99). This is consistent with in vivo data suggesting that resveratrol may act on additional sirtuins than SIRT1 or on different targets (92). Nevertheless, understanding the role of AMPK in the action of polyphenols will provide valuable information to aid decisions about whether these compounds might be used as 
additives in foods or beverages to promote health and attenuate, or delay, the onset of various diseases, including cardiovascular disease and diabetes.

\section{ROLE OF AMPK IN THE CONTROL OF GLUCOSE HOMEOSTASIS}

Glucose homeostasis is maintained by a balance between glucose production and glucose uptake by peripheral tissues. Elevated hepatic glucose production (HGP) is a major cause of fasting hyperglycemia in diabetic subjects (2). The importance of AMPK in the control of glucose output by the liver is emphasized by findings showing that pharmacological activation of AMPK leads to inhibition of HGP in vitro and in vivo. It has been first shown that systemic infusion of AICAR in normal and insulin-resistant obese rats led to the inhibition of hepatic glucose production (HGP) (63). Similarly, it was reported that AMPK activation by metformin in cultured rat hepatocytes mediates the inhibitory effects of the drug on hepatic glucose production (100). There is now good in vivo evidence from studies of mice deficient in the upstream kinase LKB1 in the liver that the blood-lowering effect of metformin is mediated by activation of the LKB1/AMPK axis (101). It has been also reported that short-term hepatic expression of a constitutively active form of the $\alpha 2$ catalytic subunit (AMPK $\alpha 2-\mathrm{CA}$ ) led to mild hypoglycemia in normal mice $(102,103)$ and abolished hyperglycemia in diabetic $o b / o b$ and STZ-induced diabetic mice (102). This hypoglycemic effect of AMPK activation is consistent with the abolition of HGP, as suggested by the down-regulation of gluconeogenic gene expression (e.g., phosphoenolpyruvate carboxykinase (PEPCK) and glucose6-phosphatase (G6Pase)) and inhibition of glucose production in hepatocytes expressing AMPK-CA or treated with AICAR (102-104). Inhibition of gluconeogenesis by AMPK is achieved at least to a large extent via the regulation of a transcriptional coactivator, transducer of regulated CREB activity 2 (TORC2) (105). TORC2 mediates CREB-dependent transcription of PGC1 $\alpha$ and its subsequent gluconeogenic targets PEPCK and G6Pase. TORC2 is regulated by multiple signaling pathways in response to changes in glucagon and insulin levels or intracellular energy status. AMPK activation causes TORC2 phosphorylation and sequesters the coactivator in the cytoplasm, thus blunting the expression of the gluconeogenic program (Figure 4). A physiological link has been established between the potent effects of various circulating adipocyte-derived hormones circulating levels and hepatic AMPK activity in the maintenance of blood glucose levels. Low blood glucose levels and reduced HGP in mice lacking resistin are likely related, at least in part, to activation of AMPK and decreased expression of gluconeogenic enzymes in the liver (106). Administration of adiponectin is known to reduce both blood glucose levels and expression of gluconeogenic genes. It has been shown that these effects required AMPK activation at least in the liver (107). According to this result, adiponectin failed to regulate $\mathrm{HGP}$ in liver-specific $\mathrm{AMPK} \alpha 2 \mathrm{KO}$ mice (108).
Skeletal muscle is the main site for glucose disposal in the body. Insulin increases glucose uptake in the muscle by stimulating the translocation of glucose transporter GLUT4 from intracellular vesicles to the cell surface. (Figure 3). It has been shown that muscular AMPK activation stimulates muscle glucose uptake either by exercise or by AICAR and this occurs through a distinct mechanism than the insulin-signaling pathway. AICAR can effectively increase glucose transport and GLUT4 translocation in skeletal muscle, not only in lean subjects but also in type 2 diabetes subjects (109). An AMPKdependant increase in glucose transport is therefore observed in insulin-resistant skeletal muscle, both in rodents and humans, providing evidence that the AMPK pathway can be activated in this case (46). Stimulation of AMPK in the muscle could be an efficient method to increase glucose uptake in an insulin-independent manner, thus bypassing defective insulin signaling, such as one observed in type 2 diabetes patients. Although the upstream stimuli that activate AMPK are relatively well known (46), the signaling mechanisms downstream of AMPK which regulate muscle glucose transport are not so well understood. It has been recently discovered that the Akt substrate of $160 \mathrm{kDa}$ (AS160/TBC1D4), downstream target of Akt, played a major role in regulating insulin-stimulated glucose uptake. Another possible downstream effector of AMPK in the regulation of muscle glucose transport is an AS160/TBC1D4 homolog, TBC1D1 (110). AS160/TBC1D4 is a Rab-GTPase activating protein that regulates the translocation of GLUT4 from intracellular vesicles to the plasma membrane by maintaining small Gproteins, known as Rab, in a GDP-bound state. The phosphorylation of AS160 at specific sites is thought to disrupt GTPase activity and allow the release of AS160 inhibition on GLUT4 vesicle intracellular localization, thus initializing the vesicle translocation (110). TBC1D1 is also a Rab-GTPase activating protein and its phosphorylation is enhanced in mouse skeletal muscle myotubes following treatment with AICAR (111). In a similar way, exercise and AICAR-induced AMPK activation caused AS160/TBC1D4 phosphorylation in skeletal muscle like insulin (28). Furthermore, AS160 phosphorylation as well as glucose uptake is increased in skeletal muscle following a resistance exercise in humans. A positive correlation between increased AS160/TBC1D4 phosphorylation and muscle glucose uptake during post-exercise recovery has been observed, as well as increased muscle AMPK $\alpha 2$ activity (112). Taken together, these results show that AMPK-induced muscle glucose uptake stimulation is mediated by AS160/TBC1D4. This represents a point of convergence connecting insulin, contraction and AMPKstimulated glucose transport. It has been observed that exercise-induced AMPK activation in muscle is diminished in both obese non-diabetic and obese type 2 diabetes subjects, but maintained in lean type 2 diabetes patients $(12,113)$. This suggests that dysregulation of the AMPK pathway may be more associated with obesity rather than with type 2 diabetes per se. This reflects impaired adaptability to utilize lipid and carbohydrate fuels and to transition between them, also referred as metabolic inflexibility (114), observed in obese and insulin resistant people. It is therefore likely that obese patients may require 


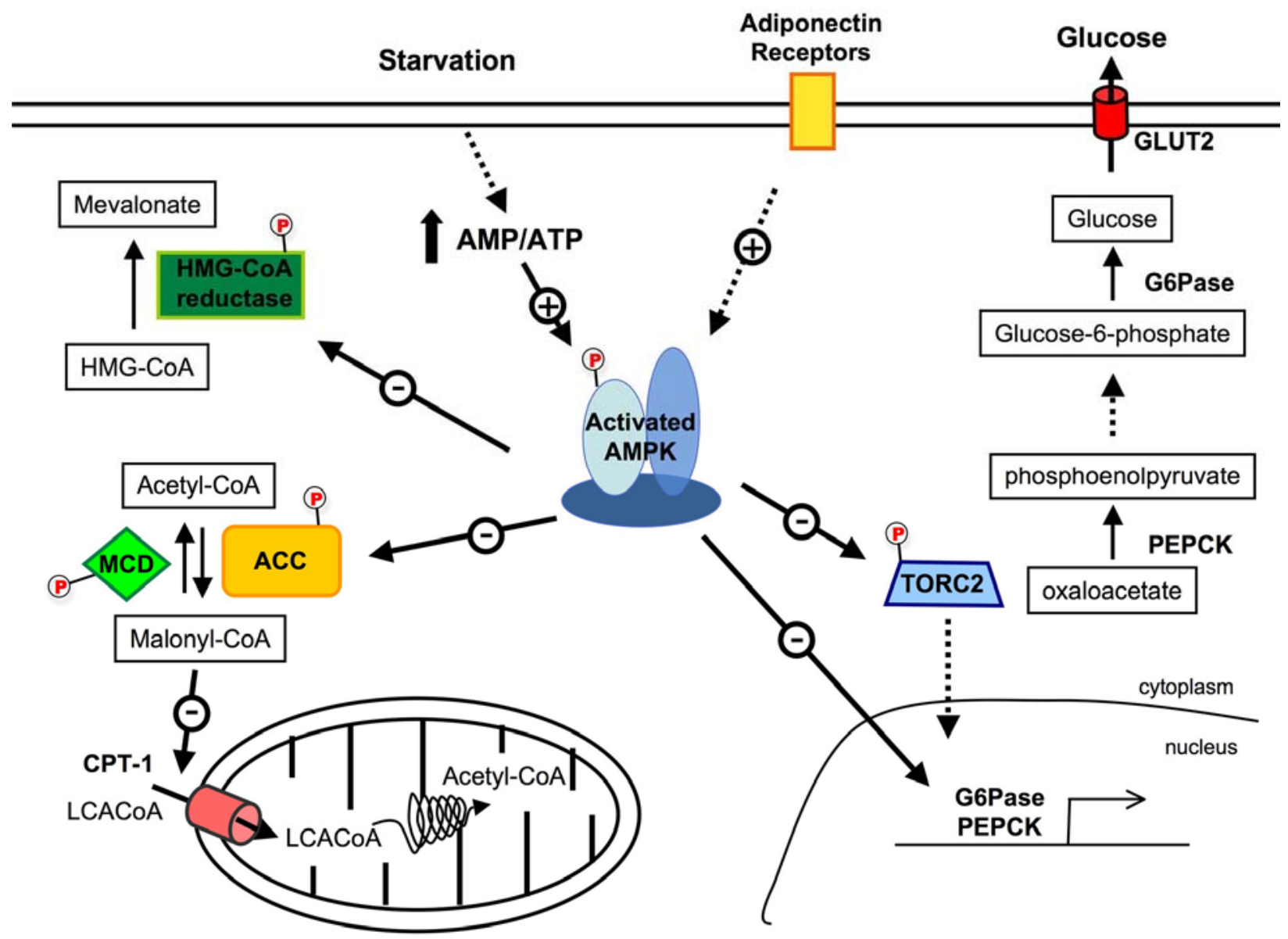

Figure 4. AMPK and the regulation of skeletal muscle metabolism. Proposed model for the role of AMPK in the regulation of lipid and glucose metabolism in skeletal muscle. AMPK activity may be increased by an altered energy nucleotide or by hormonal action. This activation of AMPK may result in an increase in glucose transport as well as an increase in fatty acid oxidation. ACC, acetyl-CoA carboxylase; AMPK, AMP-activated protein kinase; AS160, Akt substrate of 160kDa; CPT1- $\alpha$, carnitine palmitoyl transferase-1; Glut4, glucose tranporter 4; MCD, malonyl-CoA decarboxylase; PGC1 $\alpha$, PPAR $\gamma$ co-activator $1 \alpha ;$ LCACoA, Long Chain acyl CoAs.

a more intense exercise protocol to achieve the same benefits than in lean individuals (113). Consistently, in obese type 2 diabetes subjects, AS160 phosphorylation is blunted in skeletal muscle following moderate intensity exercise (113).

Several cytokines have been shown to stimulate glucose transport in muscle in an AMPK-dependent manner. Leptin is an adipokine recently shown to improve insulin action in muscle of patients with lipodystrophy, although the role of AMPK activation as mediator is not studied (115). Leptin is also known to stimulate glucose uptake in peripheral tissue $(116,117)$. It has been shown that leptin selectively stimulated AMPK $\alpha 2$ phosphorylation and activation in skeletal muscle, further confirming the role of AMPK in leptin-mediated stimulation of glucose transport (118). Adiponectin also increases glucose transport in both lean and obese skeletal muscle, although the effect is less significant in the latter (119). This suggests a possible development of adiponectin resistance related to metabolic inflexibility observed in skeletal muscle from obese individuals. Interleukin-6 (IL-6) is a proinflammatory cytokine that activates AMPK and is thought to modify insulin sensitivity. Recently, it has also been recognized as a "myokine", due to its release from the skeletal muscle during prolonged exercise (120). Muscle strips obtained from healthy young men treated with IL-6 show an increased glucose uptake concomitant with AMPK phosphorylation (121). It has been shown that IL-6stimulated glucose transport is mediated via the LKB1/AMPK/AS160 pathway. However, the same study also shows that IL-6 has a dual effect : short term IL-6 treatment is additive to insulin on activating glucose transport and AS160 phosphorylation, resulting in an improved glucose tolerance and insulin sensitivity in mice, whereas chronic exposure produces insulin resistance both in vitro and in vivo (122). It has been shown that AMPK participates in the regulation of IL-6 release from oxidative muscle. It has been also suggested that AICAR, in addition to activating AMPK, suppresses IL-6 release by an AMPK 
independent mechanism (123). Collectively these results demonstrate that AMPK plays a major role in glucose homeostasis by modulating glucose transport in skeletal muscle. Thus, AMPK could have a significant role in the modification of glucose muscle metabolism, thus establishing the AMPK pathway as an attractive target for the treatment of type 2 diabetes.

\section{ROLE OF AMPK IN THE CONTROL OF LIPID METABOLISM}

Both insulin resistance and type 2 diabetes are characterized by dyslipidemia, which is an important and common risk factor for cardiovascular disease. Diabetic dyslipidemia is a cluster of potentially atherogenic lipid and lipoprotein abnormalities that are metabolically interrelated. AMPK coordinates the changes in the hepatic lipid metabolism and, so, regulates the partitioning of fatty acids between oxidative and biosynthetic pathways. Thus, once activated, AMPK phosphorylates and inactivates a number of metabolic enzymes involved in ATP-consuming cellular events, such as 3-hydroxy-3-methylglutarylcoenzyme A reductase (HMG-CoA reductase) and acetylCoA carboxylase (ACC), key enzymes in hepatic cholesterol and fatty acid synthesis (Figure 4). In addition, AMPK suppresses expression of lipogenesis-associated genes such as fatty acid synthase, pyruvate kinase and ACC (102, 124-127). ACC is an important rate-controlling enzyme for the synthesis of malonyl-CoA, which is both a critical precursor for the biosynthesis of fatty acids and a potent inhibitor of mitochondrial fatty acid oxidation. Inhibition of ACC by AMPK leads to a drop in malonylCoA content and a subsequent decrease in fatty acid synthesis and increase in fatty acid oxidation, thus reducing excessive storage of triglycerides. Malonyl CoA decarboxylase (MCD), an enzyme involved in the turnover of malonyl-CoA, has been shown to be activated by AMPK in response to energy depletion, resulting in reduced malonyl CoA levels and increased fatty acid oxidation (128). Consistently, overexpression of AMPK $\alpha 2-C A$ in the liver, treatment with AICAR or metformin in lean and obese rodents increase plasma $\beta$-hydroxybutyrate levels, suggesting elevated hepatic lipid oxidation, concomitantly with a decrease in plasma triglyceride levels $(63,100,102)$. Conversely, liver-specific AMPK $\alpha 2$ deletion leads to increased plasma triglyceride levels and enhances hepatic lipogenesis (108). These data emphasizes the critical role for AMPK in the control of hepatic lipid deposition via decreased lipogenesis and increased lipid oxidation, thus improving lipid profile in type 2 diabetes. In addition, AMPK also emerged as a key player in the regulation of fatty acid oxidation in skeletal muscle (Figure 3 ). In rodent skeletal muscle, stimulation of AMPK by AICAR increased the oxidation of palmitate $(129,130)$. Leptin, an adipocytesecreted hormone that plays a pivotal role in regulation of energy expenditure, was found to increase fatty acid oxidation in skeletal muscle by activating AMPK (118). Leptin activates AMPK by a dual effect, i.e. early and transient activation of AMPK by leptin directly at the level of muscle and a more sustained activation mediated through the hypothalamic-sympathetic nervous system axis and $\alpha$-adrenergic receptors in muscle (118). Mice harboring a gain-of-function of the $\gamma 3$ subunit (R225Q) in skeletal muscle demonstrate lower intramuscular TG content, increased lipid oxidation and protection against diet-induced insulin resistance (131). As in the liver, AMPK enhances fatty acid oxidation by inactivating ACC, thereby reducing the synthesis of malonyl CoA. However, recent studies using mAMPK-KD mice indicate that AMPK-independent pathways can regulate skeletal muscle fatty acid oxidation (132). Furthermore, incubation of isolated rat muscle with both AICAR and electrical stimulation result in higher fatty acid oxidation than for each condition alone (133). In human skeletal muscle, the connection between changes in AMPK activation and fatty acid oxidation during exercise is not clear $(134,135)$.

\section{MANAGEMENT OF FATTY LIVER DISEASE BY AMPK ACTIVATION}

One of the critical complications of type 2 diabetes is nonalcoholic fatty liver disease (NAFDL), a disorder of triacylglycerol accumulation in the liver that has potential to develop into end stage liver failure. It has been proposed that steatosis primed the liver to progress to more severe liver pathologies when individuals were exposed to subsequent metabolic and/or environmental stresses. Insulin resistance is a major feature of NAFDL and studies in humans and various animal models suggest that efforts to enhance insulin sensitivity might improve fatty liver disease. The efficacy of insulin-sensitizer metformin as a treatment for this disease is confirmed in obese ob/ob mice, which develop hyperinsulinemia, insulin resistance and fatty livers (136). Similarly, adiponectin treatment restores insulin sensitivity and decreases hepatic steatosis by lowering the triglyceride content in the liver of obese mice (137). Metabolic improvement of adiponectin is linked to an activation of AMPK in the liver that decreases fatty acid biosynthesis and increases mitochondrial fatty acids oxidation (138). This is confirmed by a decrease in liver triglycerides content in lean and obese rodents during AICAR infusion (63) and treatment with small-molecule AMPK activators (139). Increased intracellular fat content in liver associated with insulin resistance leads to the hypothesis that a mitochondrial dysfunction in substrate oxidation is a primary defect in insulin resistant. It was recently demonstrated that activation of AMPK by RSV protected against lipid accumulation in the liver of diabetic mice (88), in association with increased mitochondrial number (87) and SIRT1-dependent deacetylation of peroxisome proliferator-activated receptor coactivator (PGC)-1 $\alpha$, a master regulator of mitochondrial biogenesis (87, 140). Hepatocytes deleted for both AMPK catalytic subunits have reduced mitochondrial biogenesis as suggested by decreased transcript and protein expression of key mitochondrial constituents such as PGC- $1 \alpha$, cytochrome c oxidase I (COX I), COX IV and cytochrome c genes (141). These results emphasize the importance of AMPK in the regulation of cellular energy homeostasis through the control of adaptive mitochondrial function. However, the role of the AMPK system in the treatment of fatty liver diseases remains to be clearly established in humans. Its importance is strongly indicated by recent studies with AICAR infusion in type 2 diabetic patients. 
This study reported that AICAR infusion resulted in significant decline in circulating plasma non-esterified fatty acids (NEFA) levels, suggesting stimulation of hepatic fatty acid oxidation and/or reduction in whole body lipolytic rate (142).

\section{ROLE OF AMPK IN THE REGULATION OF $\beta$ - CELL FUNCTION}

Insulin resistance and insulin secretion defects are major risk factors for type 2 diabetes (143). The pathogenesis of type 2 diabetes is associated with different degrees of $\beta$-cell failure relative to varying degrees of insulin resistance. A progressive decrease of $\beta$-cell function leads to glucose intolerance, which is followed by type 2 diabetes that inexorably aggravates with time (144). According to the glucolipotoxicity hypothesis (145), chronic high glucose dramatically influences $\beta$-cell metabolism and results in an increase of cytosolic fatty acyl-CoA partitioning toward potentially toxic cellular products (e.g., diacylglycerol, ceramide and lipid peroxides). This leads to impaired insulin secretory response to glucose and ultimately in apoptosis. Evidence from recent literature clearly demonstrated that changes in AMPK signaling are important in the pathogenesis of both $\beta$-cell glucolipotoxicity and type 2 diabetes. Metformin, TZDs and AICAR treatments favor fatty acid $\beta$-oxidation and prevent glucolipotoxicity-induced insulin secretory dysfunction in $\beta$-cells (146-148). These results have been confirmed by using adenovirus-mediated over-expression of AMPK $\alpha 1-C A$ in $\beta$-cell (149). A recent study reported that AICAR dose-dependently improves $\beta$-cell function without changing intracellular TG levels and may act through reducing apoptosis induced by prolonged hyperglycemia. However, the role of AMPK in the control of $\beta$-cell death remains controversial (150-155).

In $\beta$-cells, AMPK activity is rapidly decreased by elevations in glucose concentration over the physiological range indicating that AMPK could play a role in insulin release acting as a fuel sensor (156-158). Activation of AMPK by AICAR, metformin, TZDs and berberine or by overexpression of AMPK $\alpha 1-\mathrm{CA}$ markedly reduces glucose-stimulated insulin secretion in $\beta$-cell lines and in rodent and human islets $(149,156,159,160)$. Conversely, overexpression of a dominant-negative form of AMPK stimulates insulin release at low glucose concentrations $(157,161)$. These data suggest that activation of AMPK inhibits insulin release to maintain glucose homeostasis. Thus, inhibition rather than activation of AMPK would be desirable for the treatment of type 2 diabetes in order to reverse the decline in glucose-induced insulin secretion. Surprinsingly, it has been reported that agents that suppress insulin secretion, such as diazoxide, improve glucose tolerance and $\beta$-cell function (162). This effect is thought to be mediated via hyperpolarization of $\beta$-cells, thereby providing $\beta$-cell rest by reducing insulin release and could protect against the negative effects of overstimulation. One important point to take into account in this context is the role of pancreatic AMPK during the adaptation of insulin secretion in front of various degrees of insulin resistance during the onset of type 2 diabetes. First, AMPK-mediated suppression of insulin release could directly counteracts glucolipotoxicity, which may prevent functional exhaustion of $\beta$-cells in prediabetic states. A decrease in $\beta$-cell mass is likely to play a role in the pathogenesis of human type 2 diabetes (163) as it does in rodent models of the disease (164). Second, inhibition of insulin release would reduce the pathological basal hyperinsulinemia and markedly increase insulin sensitivity and hence improve $\beta$-cell function and mass. Consistently, systemic AICAR infusion in prediabetic Zucker fatty rats prevents the development of hyperglycemia and preserved $\beta$-cell mass (66).

\section{MANAGEMENT OF CARDIOVASCULAR DISEASES BY AMPK ACTIVATION}

Type 2 diabetes is associated with an increased risk of cardiovascular disease and coronary heart disease mortality. The high energy demands of the heart are primarily met by the metabolism of fatty acids and glucose, both processes being regulated by AMPK. Indeed, AMPK stimulates glycolysis and sustains energy supply during ischemic stress. Promotion of glucose oxidation or inhibition of fatty acid oxidation in ischemic/reperfused hearts could be a promising novel therapeutic approach to myocardial ischemic conditions. Such a mechanism has been demonstrated during the phenomenon called ischemic preconditioning. Brief episodes of myocardial ischemia render the heart more resistant to subsequent ischemic episodes (165). Ischemic preconditioning is known to induce endogenous protective mechanisms in the heart. It activates AMPK in a PKC-dependent manner and promotes glucose utilization in myocardial cells, supporting resistance toward ischemic consequences (166). Thus, AMPK activators could be of particular interest for the management of myocardial ischemia. Attractively, it has been reported that adiponectin protects the heart from ischemia by activating AMPK and increasing the energy supply to heart cells (167). In addition, it has also been reported that adiponectin attenuates cardiac hypertrophy through activation of AMPK signaling pathway $(168,169)$.

The presence of endothelial cell dysfunction in patients with type 2 diabetes, as manifested by impaired vascular relaxation or increase in circulating vascular cell adhesion molecules is thought to be one component of the inflammatory process initiating atherogenesis. In this respect, metformin has been proposed to improve endothelium function in diabetes by favoring phosphorylation of endothelial NO synthase (eNOS) by AMPK activation (23). Metformin was also shown to relax endothelium-denuded rat aortic rings pre-contracted with phenylephrine, showing that AMPK can induce vasorelaxation in an endothelium- and NOS-independent manner (170). Thus, vascular AMPK could be involved in the metabolic regulation of vascular tone. AMPK activation in response to hypoxia or metabolic challenge can induce vasorelaxation of big vessels $(171,172)$, thereby favoring blood flow. Interestingly, AMPK-dependent adiponectin vascular effects have been demonstrated for angiogenic repair in an ischemic hind limbs model (173). 


\section{CONCLUSIONS AND MEDICAL PERSPECTIVES}

Because of its global favourable effects on energy metabolism pathways, it is tempting to consider AMPK as a potential therapeutic target in the prevention and the treatment of type 2 diabetes and insulin resistance. A large number of AMPK activators have been employed with promising results in diabetic animal models and these encouraging results have provided the rationale for the development of new pharmacological (e.g., A769662) but also nutritional (e.g., polyphenols) AMPK activators. AMPK activation in the liver and skeletal muscle entails metabolic changes that are beneficial for the diabetic patients with inhibition of HGP and stimulation of glucose uptake in skeletal muscle which help to maintain glycemia. However, some of the effects of AMPK activation in other organs or tissues should be carefully evaluated. The widespread cellular functions of AMPK make its selective targeting in therapeutics a difficult one, with simultaneous advantageous and deleterious consequences being possible. Thus, care should be taken that other metabolic effects due to AMPK activation could be detrimental for diabetic patients. One of the major caveats in the use of AMPK activators is their possible role in the regulation of food intake. Stimulation of AMPK expressed in specific nuclei of the hypothalamus has been shown to increase food intake (174). Thus, the ideal AMPK activators will be administered by the oral route, activate AMPK at low concentration and be effective in specific target organs, such as the liver and skeletal muscle but not the hypothalamus, and will also have minimal off-targets. An emerging concept is the use of tissue-specific pharmacological activation of AMPK that could be achieved through isoform-specific activation of AMPK. Interestingly, the small AMPK activator A-769662 is mainly targeted to the liver (175) and treatment of animal models with this compound recapitulates many of the effects expected for a specific hepatic AMPK activation (102). Similarly, it appears that the major effect of intravenous AICAR infusion in type 2 diabetic patients is restricted to the liver with inhibition of hepatic glucose output and decreased blood glucose levels (142). Curiously, AMPK activation is not evident in muscle biopsies from healthy volunteers (176) or diabetic patients (142) in response to AICAR infusion. These human data raise the question about the effective dose in producing a detectable AMPK activation in skeletal muscle and the benefit in term of glucoregulation in diabetic patients.

\section{ACKNOWLEDGMENTS}

The authors were supported by the EXGENESIS Integrated Project (LSHM-CT- 2004-005272) funded by the European Commission, Programme Nationale de Recherche sur le Diabète, Agence Nationale de la Recherche, Association de Langue Française pour l'Etude du Diabète et des Maladies Métaboliques and Institut Benjamin Delessert. R.M. was supported by postdoctoral fellowship from the European Commission.

\section{4- REFERENCES}

1. R. R. Wing, M. G. Goldstein, K. J. Acton, L. L. Birch, J. M. Jakicic, J. F. Sallis, Jr., D. Smith-West, R. W. Jeffery and R. S. Surwit: Behavioral science research in diabetes: lifestyle changes related to obesity, eating behavior, and physical activity. Diabetes Care, 24 (1), 117-23 (2001)

2. A. R. Saltiel and C. R. Kahn: Insulin signalling and the regulation of glucose and lipid metabolism. Nature, 414 (6865), 799-806 (2001)

3. X. R. Pan, G. W. Li, Y. H. Hu, J. X. Wang, W. Y. Yang, Z. X. An, Z. X. Hu, J. Lin, J. Z. Xiao, H. B. Cao, P. A. Liu, X. G. Jiang, Y. Y. Jiang, J. P. Wang, H. Zheng, H. Zhang, P. H. Bennett and B. V. Howard: Effects of diet and exercise in preventing NIDDM in people with impaired glucose tolerance. The Da Qing IGT and Diabetes Study. Diabetes Care, 20 (4), 537-44 (1997)

4. J. Tuomilehto, J. Lindstrom, J. G. Eriksson, T. T. Valle, H. Hamalainen, P. Ilanne-Parikka, S. KeinanenKiukaanniemi, M. Laakso, A. Louheranta, M. Rastas, V. Salminen and M. Uusitupa: Prevention of type 2 diabetes mellitus by changes in lifestyle among subjects with impaired glucose tolerance. $N$ Engl J Med, 344 (18), 134350 (2001)

5. W. C. Knowler, E. Barrett-Connor, S. E. Fowler, R. F. Hamman, J. M. Lachin, E. A. Walker and D. M. Nathan: Reduction in the incidence of type 2 diabetes with lifestyle intervention or metformin. $N$ Engl J Med, 346 (6), 393-403 (2002)

6. C. Hayes and A. Kriska: Role of physical activity in diabetes management and prevention. J Am Diet Assoc, 108 (4 Suppl 1), S19-23 (2008)

7. R. J. Sigal, G. P. Kenny, D. H. Wasserman and C. Castaneda-Sceppa: Physical activity/exercise and type 2 diabetes. Diabetes Care, 27 (10), 2518-39 (2004)

8. S. M. Grundy, A. Garber, R. Goldberg, S. Havas, R. Holman, C. Lamendola, W. J. Howard, P. Savage, J. Sowers and G. L. Vega: Prevention Conference VI: Diabetes and Cardiovascular Disease: Writing Group IV: lifestyle and medical management of risk factors. Circulation, 105 (18), e153-8 (2002)

9. J. B. Buse, H. N. Ginsberg, G. L. Bakris, N. G. Clark, F. Costa, R. Eckel, V. Fonseca, H. C. Gerstein, S. Grundy, R. W. Nesto, M. P. Pignone, J. Plutzky, D. Porte, R. Redberg, K. F. Stitzel and N. J. Stone: Primary prevention of cardiovascular diseases in people with diabetes mellitus: a scientific statement from the American Heart Association and the American Diabetes Association. Diabetes Care, 30 (1), 162-72 (2007)

10. N. B. Ruderman, H. Park, V. K. Kaushik, D. Dean, S. Constant, M. Prentki and A. K. Saha: AMPK as a metabolic switch in rat muscle, liver and adipose tissue after exercise. Acta Physiol Scand, 178 (4), 435-42 (2003) 
11. K. R. Segal, A. Edano, A. Abalos, J. Albu, L. Blando, M. B. Tomas and F. X. Pi-Sunyer: Effect of exercise training on insulin sensitivity and glucose metabolism in lean, obese, and diabetic men. J Appl Physiol, 71 (6), 2402-11 (1991)

12. N. Musi, N. Fujii, M. F. Hirshman, I. Ekberg, S. Froberg, O. Ljungqvist, A. Thorell and L. J. Goodyear: AMP-activated protein kinase (AMPK) is activated in muscle of subjects with type 2 diabetes during exercise. Diabetes, 50 (5), 921-7 (2001)

13. J. A. Hawley and S. J. Lessard: Exercise traininginduced improvements in insulin action. Acta Physiol (Oxf), 192 (1), 127-35 (2008)

14. I. W. Campbell: Long-term glycaemic control with pioglitazone in patients with type 2 diabetes. Int $\mathrm{J}$ Clin Pract, 58 (2), 192-200 (2004)

15. S. A. Smith, L. E. Porter, N. Biswas and M. I. Freed: Rosiglitazone, but not glyburide, reduces circulating proinsulin and the proinsulin:insulin ratio in type 2 diabetes. J Clin Endocrinol Metab, 89 (12), 6048-53 (2004)

16. T. A. Buchanan, A. H. Xiang, R. K. Peters, S. L. Kjos, A. Marroquin, J. Goico, C. Ochoa, S. Tan, K. Berkowitz, H. N. Hodis and S. P. Azen: Preservation of pancreatic beta-cell function and prevention of type 2 diabetes by pharmacological treatment of insulin resistance in high-risk hispanic women. Diabetes, 51 (9), 2796-803 (2002)

17. A. H. Xiang, R. K. Peters, S. L. Kjos, A. Marroquin, J. Goico, C. Ochoa, M. Kawakubo and T. A. Buchanan: Effect of pioglitazone on pancreatic beta-cell function and diabetes risk in Hispanic women with prior gestational diabetes. Diabetes, 55 (2), 517-22 (2006)

18. H. C. Gerstein, S. Yusuf, J. Bosch, J. Pogue, P. Sheridan, N. Dinccag, M. Hanefeld, B. Hoogwerf, M. Laakso, V. Mohan, J. Shaw, B. Zinman and R. R. Holman: Effect of rosiglitazone on the frequency of diabetes in patients with impaired glucose tolerance or impaired fasting glucose: a randomised controlled trial. Lancet, 368 (9541), 1096-105 (2006)

19. A. R. Nawrocki, M. W. Rajala, E. Tomas, U. B. Pajvani, A. K. Saha, M. E. Trumbauer, Z. Pang, A. S. Chen, N. B. Ruderman, H. Chen, L. Rossetti and P. E. Scherer: Mice lacking adiponectin show decreased hepatic insulin sensitivity and reduced responsiveness to peroxisome proliferator-activated receptor gamma agonists. J Biol Chem, 281 (5), 2654-60 (2006)

20. N. Maeda, M. Takahashi, T. Funahashi, S. Kihara, H. Nishizawa, K. Kishida, H. Nagaretani, M. Matsuda, R. Komuro, N. Ouchi, H. Kuriyama, K. Hotta, T. Nakamura, I. Shimomura and Y. Matsuzawa: PPARgamma ligands increase expression and plasma concentrations of adiponectin, an adipose-derived protein. Diabetes, 50 (9), 2094-9 (2001)
21. R. G. Dluhy and G. T. McMahon: Intensive glycemic control in the ACCORD and ADVANCE trials. $N$ Engl $J$ Med, 358 (24), 2630-3 (2008)

22. P. J. Grant: Beneficial effects of metformin on haemostasis and vascular function in man. Diabetes Metab, 29 (4 Pt 2), 6S44-52 (2003)

23. B. J. Davis, Z. Xie, B. Viollet and M. H. Zou: Activation of the AMP-activated kinase by antidiabetes drug metformin stimulates nitric oxide synthesis in vivo by promoting the association of heat shock protein 90 and endothelial nitric oxide synthase. Diabetes, 55 (2), 496-505 (2006)

24. T. Inoue, N. Kotooka, T. Morooka, H. Komoda, T. Uchida, Y. Aso, T. Inukai, T. Okuno and K. Node: High molecular weight adiponectin as a predictor of long-term clinical outcome in patients with coronary artery disease. $\mathrm{Am} \mathrm{J}$ Cardiol, 100 (4), 569-74 (2007)

25. A. T. Gonon, U. Widegren, A. Bulhak, F. Salehzadeh, J. Persson, P. O. Sjoquist and J. Pernow: Adiponectin protects against myocardial ischaemia-reperfusion injury via AMP-activated protein kinase, Akt, and nitric oxide. Cardiovasc Res, 78 (1), 116-22 (2008)

26. M. Naruszewicz, I. Laniewska, B. Millo and M. Dluzniewski: Combination therapy of statin with flavonoids rich extract from chokeberry fruits enhanced reduction in cardiovascular risk markers in patients after myocardial infraction (MI). Atherosclerosis, 194 (2), e17984 (2007)

27. J. B. Birk and J. F. Wojtaszewski: Predominant alpha2/beta2/gamma3 AMPK activation during exercise in human skeletal muscle. J Physiol, 577 (Pt 3), 1021-32 (2006)

28. J. T. Treebak, J. B. Birk, A. J. Rose, B. Kiens, E. A. Richter and J. F. Wojtaszewski: AS160 phosphorylation is associated with activation of alpha2beta2gamma1- but not alpha2beta2gamma3-AMPK trimeric complex in skeletal muscle during exercise in humans. Am $J$ Physiol Endocrinol Metab, 292 (3), E715-22 (2007)

29. S. K. Hanks, A. M. Quinn and T. Hunter: The protein kinase family: conserved features and deduced phylogeny of the catalytic domains. Science, 241 (4861), 42-52 (1988)

30. S. A. Hawley, M. Davison, A. Woods, S. P. Davies, R. K. Beri, D. Carling and D. G. Hardie: Characterization of the AMP-activated protein kinase kinase from rat liver and identification of threonine 172 as the major site at which it phosphorylates AMP-activated protein kinase. J Biol Chem, 271 (44), 27879-87 (1996)

31. S. C. Stein, A. Woods, N. A. Jones, M. D. Davison and D. Carling: The regulation of AMP-activated protein kinase by phosphorylation. Biochem J, 345 Pt 3, 437-43 (2000)

32. B. E. Crute, K. Seefeld, J. Gamble, B. E. Kemp and L. A. Witters: Functional domains of the alphal catalytic 
subunit of the AMP-activated protein kinase. $J$ Biol Chem, 273 (52), 35347-54 (1998)

33. T. Pang, B. Xiong, J. Y. Li, B. Y. Qiu, G. Z. Jin, J. K. Shen and J. Li: Conserved alpha-helix acts as autoinhibitory sequence in AMP-activated protein kinase alpha subunits. J Biol Chem, 282 (1), 495-506 (2007)

34. I. Salt, J. W. Celler, S. A. Hawley, A. Prescott, A. Woods, D. Carling and D. G. Hardie: AMP-activated protein kinase: greater AMP dependence, and preferential nuclear localization, of complexes containing the alpha2 isoform. Biochem J, 334 ( Pt 1), 177-87 (1998)

35. A. Woods, P. C. Cheung, F. C. Smith, M. D. Davison, J. Scott, R. K. Beri and D. Carling: Characterization of AMP-activated protein kinase beta and gamma subunits. Assembly of the heterotrimeric complex in vitro. $J$ Biol Chem, 271 (17), 10282-90 (1996)

36. T. J. Iseli, M. Walter, B. J. van Denderen, F. Katsis, L. A. Witters, B. E. Kemp, B. J. Michell and D. Stapleton: AMP-activated protein kinase beta subunit tethers alpha and gamma subunits via its C-terminal sequence (186-270). J Biol Chem, 280 (14), 13395-400 (2005)

37. E. R. Hudson, D. A. Pan, J. James, J. M. Lucocq, S. A. Hawley, K. A. Green, O. Baba, T. Terashima and D. G. Hardie: A novel domain in AMP-activated protein kinase causes glycogen storage bodies similar to those seen in hereditary cardiac arrhythmias. Curr Biol, 13 (10), 861-6 (2003)

38. G. Polekhina, A. Gupta, B. J. Michell, B. van Denderen, S. Murthy, S. C. Feil, I. G. Jennings, D. J. Campbell, L. A. Witters, M. W. Parker, B. E. Kemp and D. Stapleton: AMPK beta subunit targets metabolic stress sensing to glycogen. Curr Biol, 13 (10), 867-71 (2003)

39. B. E. Kemp: Bateman domains and adenosine derivatives form a binding contract. J Clin Invest, 113 (2), 182-4 (2004)

40. P. C. Cheung, I. P. Salt, S. P. Davies, D. G. Hardie and D. Carling: Characterization of AMP-activated protein kinase gamma-subunit isoforms and their role in AMP binding. Biochem J, 346 Pt 3, 659-69 (2000)

41. J. W. Scott, S. A. Hawley, K. A. Green, M. Anis, G. Stewart, G. A. Scullion, D. G. Norman and D. G. Hardie: CBS domains form energy-sensing modules whose binding of adenosine ligands is disrupted by disease mutations. $J$ Clin Invest, 113 (2), 274-84 (2004)

42. M. J. Rudolph, G. A. Amodeo, Y. Bai and L. Tong: Crystal structure of the protein kinase domain of yeast AMP-activated protein kinase Snf1. Biochem Biophys Res Commun, 337 (4), 1224-8 (2005)

43. G. Polekhina, A. Gupta, B. J. van Denderen, S. C. Feil, B. E. Kemp, D. Stapleton and M. W. Parker: Structural basis for glycogen recognition by AMP-activated protein kinase. Structure, 13 (10), 1453-62 (2005)
44. B. Xiao, R. Heath, P. Saiu, F. C. Leiper, P. Leone, C. Jing, P. A. Walker, L. Haire, J. F. Eccleston, C. T. Davis, S. R. Martin, D. Carling and S. J. Gamblin: Structural basis for AMP binding to mammalian AMPactivated protein kinase. Nature, 449 (7161), 496-500 (2007)

45. M. Suter, U. Riek, R. Tuerk, U. Schlattner, T. Wallimann and D. Neumann: Dissecting the role of 5'AMP for allosteric stimulation, activation, and deactivation of AMP-activated protein kinase. $J$ Biol Chem, 281 (43), 32207-16 (2006)

46. D. G. Hardie: The AMP-activated protein kinase pathway--new players upstream and downstream. $J$ Cell Sci, 117 (Pt 23), 5479-87 (2004)

47. S. A. Hawley, J. Boudeau, J. L. Reid, K. J. Mustard, L. Udd, T. P. Makela, D. R. Alessi and D. G. Hardie: Complexes between the LKB1 tumor suppressor, STRAD alpha/beta and MO25 alpha/beta are upstream kinases in the AMP-activated protein kinase cascade. $J$ Biol, 2 (4), 28 (2003)

48. R. J. Shaw, M. Kosmatka, N. Bardeesy, R. L. Hurley, L. A. Witters, R. A. DePinho and L. C. Cantley: The tumor suppressor LKB1 kinase directly activates AMP-activated kinase and regulates apoptosis in response to energy stress. Proc Natl Acad Sci U S A, 101 (10), 3329-35 (2004)

49. A. Woods, S. R. Johnstone, K. Dickerson, F. C. Leiper, L. G. Fryer, D. Neumann, U. Schlattner, T. Wallimann, M. Carlson and D. Carling: LKB1 is the upstream kinase in the AMP-activated protein kinase cascade. Curr Biol, 13 (22), 2004-8 (2003)

50. S. A. Hawley, D. A. Pan, K. J. Mustard, L. Ross, J. Bain, A. M. Edelman, B. G. Frenguelli and D. G. Hardie: Calmodulin-dependent protein kinase kinase-beta is an alternative upstream kinase for AMP-activated protein kinase. Cell Metab, 2 (1), 9-19 (2005)

51. A. Woods, K. Dickerson, R. Heath, S. P. Hong, M. Momcilovic, S. R. Johnstone, M. Carlson and D. Carling: $\mathrm{Ca} 2+/$ calmodulin-dependent protein kinase kinase-beta acts upstream of AMP-activated protein kinase in mammalian cells. Cell Metab, 2 (1), 21-33 (2005)

52. R. L. Hurley, K. A. Anderson, J. M. Franzone, B. E. Kemp, A. R. Means and L. A. Witters: The $\mathrm{Ca} 2+/$ calmodulin-dependent protein kinase kinases are AMP-activated protein kinase kinases. $J$ Biol Chem, 280 (32), 29060-6 (2005)

53. F. Lan, J. M. Cacicedo, N. Ruderman and Y. Ido: SIRT1 modulation of the acetylation status, cytosolic localization and activity of LKB1; possible role in AMPactivated protein kinase activation. J Biol Chem 283 (41), 27628-35 (2008)

54. U. Riek, R. Scholz, P. Konarev, A. Rufer, M. Suter, A. Nazabal, P. Ringler, M. Chami, S. A. Muller, D. Neumann, 
M. Forstner, M. Hennig, R. Zenobi, A. Engel, D. Svergun, U. Schlattner and T. Wallimann: Structural properties of AMP-activated protein kinase: dimerization, molecular shape, and changes upon ligand binding. J Biol Chem, 283 (26), 18331-43 (2008)

55. M. J. Sanders, P. O. Grondin, B. D. Hegarty, M. A. Snowden and D. Carling: Investigating the mechanism for AMP activation of the AMP-activated protein kinase cascade. The Biochemical journal, 403 (1), 139-48 (2007)

56. T. Hayashi, M. F. Hirshman, E. J. Kurth, W. W. Winder and L. J. Goodyear: Evidence for 5' AMP-activated protein kinase mediation of the effect of muscle contraction on glucose transport. Diabetes, 47 (8), 1369-73 (1998)

57. J. S. Fisher, J. Gao, D. H. Han, J. O. Holloszy and L. A. Nolte: Activation of AMP kinase enhances sensitivity of muscle glucose transport to insulin. Am $J$ Physiol Endocrinol Metab, 282 (1), E18-23 (2002)

58. V. A. Narkar, M. Downes, R. T. Yu, E. Embler, Y. X. Wang, E. Banayo, M. M. Mihaylova, M. C. Nelson, Y. Zou, H. Juguilon, H. Kang, R. J. Shaw and R. M. Evans: AMPK and PPARdelta agonists are exercise mimetics. Cell, 134 (3), 405-15 (2008)

59. N. Fujii, M. F. Hirshman, E. M. Kane, R. C. Ho, L. E. Peter, M. M. Seifert and L. J. Goodyear: AMP-activated protein kinase alpha2 activity is not essential for contraction- and hyperosmolarity-induced glucose transport in skeletal muscle. J Biol Chem, 280 (47), 39033-41 (2005)

60. S. B. Jorgensen, B. Viollet, F. Andreelli, C. Frosig, J. B. Birk, P. Schjerling, S. Vaulont, E. A. Richter and J. F. Wojtaszewski: Knockout of the alpha2 but not alpha1 5'AMP-activated protein kinase isoform abolishes 5aminoimidazole-4-carboxamide-1-beta-4-ribofuranosidebut not contraction-induced glucose uptake in skeletal muscle. J Biol Chem, 279 (2), 1070-9 (2004)

61. J. Mu, E. R. Barton and M. J. Birnbaum: Selective suppression of AMP-activated protein kinase in skeletal muscle: update on 'lazy mice'. Biochem Soc Trans, 31 (Pt 1), 236-41 (2003)

62. N. Simard-Lefort, E. St-Amand, S. Morasse, C. H. Cote and A. Marette: The \{alpha\} subunit of AMPK is essential for submaximal contraction-mediated glucose transport in skeletal muscle in vitro \{alpha\}. Am J Physiol Endocrinol Metab (2008)

63. R. Bergeron, S. F. Previs, G. W. Cline, P. Perret, R. R. Russell, 3rd, L. H. Young and G. I. Shulman: Effect of 5aminoimidazole-4-carboxamide-1-beta-D-ribofuranoside infusion on in vivo glucose and lipid metabolism in lean and obese Zucker rats. Diabetes, 50 (5), 1076-82 (2001)

64. E. S. Buhl, N. Jessen, R. Pold, T. Ledet, A. Flyvbjerg, S. B. Pedersen, O. Pedersen, O. Schmitz and S. Lund: Long-term AICAR administration reduces metabolic disturbances and lowers blood pressure in rats displaying features of the insulin resistance syndrome. Diabetes, 51 (7), 2199-206 (2002)

65. M. A. Iglesias, J. M. Ye, G. Frangioudakis, A. K. Saha, E. Tomas, N. B. Ruderman, G. J. Cooney and E. W. Kraegen: AICAR administration causes an apparent enhancement of muscle and liver insulin action in insulinresistant high-fat-fed rats. Diabetes, 51 (10), 2886-94 (2002)

66. R. Pold, L. S. Jensen, N. Jessen, E. S. Buhl, O. Schmitz, A. Flyvbjerg, N. Fujii, L. J. Goodyear, C. F. Gotfredsen, C. L. Brand and S. Lund: Long-term AICAR administration and exercise prevents diabetes in ZDF rats. Diabetes, 54 (4), 928-34 (2005)

67. X. M. Song, M. Fiedler, D. Galuska, J. W. Ryder, M. Fernstrom, A. V. Chibalin, H. Wallberg-Henriksson and J. R. Zierath: 5-Aminoimidazole-4-carboxamide ribonucleoside treatment improves glucose homeostasis in insulin-resistant diabetic (ob/ob) mice. Diabetologia, 45 (1), 56-65 (2002)

68. N. Fujii, R. C. Ho, Y. Manabe, N. Jessen, T. Toyoda, W. L. Holland, S. A. Summers, M. F. Hirshman and L. J. Goodyear: Ablation of AMP-activated Protein Kinase \{alpha\} 2 Activity Exacerbates Insulin Resistance Induced by High-fat Feeding of Mice. Diabetes (2008)

69. J. L. Smith, P. B. Patil and J. S. Fisher: AICAR and hyperosmotic stress increase insulin-stimulated glucose transport. J Appl Physiol, 99 (3), 877-83 (2005)

70. B. F. Holmes, E. J. Kurth-Kraczek and W. W. Winder: Chronic activation of 5'-AMP-activated protein kinase increases GLUT-4, hexokinase, and glycogen in muscle. J Appl Physiol, 87 (5), 1990-5 (1999)

71. R. Bergeron, J. M. Ren, K. S. Cadman, I. K. Moore, P. Perret, M. Pypaert, L. H. Young, C. F. Semenkovich and G. I. Shulman: Chronic activation of AMP kinase results in NRF-1 activation and mitochondrial biogenesis. Am J Physiol Endocrinol Metab, 281 (6), E1340-6 (2001)

72. W. W. Winder, B. F. Holmes, D. S. Rubink, E. B. Jensen, M. Chen and J. O. Holloszy: Activation of AMP-activated protein kinase increases mitochondrial enzymes in skeletal muscle. J Appl Physiol, 88 (6), 2219-26 (2000)

73. H. Zong, J. M. Ren, L. H. Young, M. Pypaert, J. Mu, M. J. Birnbaum and G. I. Shulman: AMP kinase is required for mitochondrial biogenesis in skeletal muscle in response to chronic energy deprivation. Proc Natl Acad Sci U S A, 99 (25), 15983-7 (2002)

74. S. Jager, C. Handschin, J. St-Pierre and B. M. Spiegelman: AMP-activated protein kinase (AMPK) action in skeletal muscle via direct phosphorylation of PGC-1alpha. Proc Natl Acad Sci U S A, 104 (29), 12017-22 (2007)

75. B. F. Holmes, D. B. Lang, M. J. Birnbaum, J. Mu and G. L. Dohm: AMP kinase is not required for the GLUT4 
response to exercise and denervation in skeletal muscle. $\mathrm{Am}$ J Physiol Endocrinol Metab, 287 (4), E739-43 (2004)

76. S. B. Jorgensen, J. F. Wojtaszewski, B. Viollet, F. Andreelli, J. B. Birk, Y. Hellsten, P. Schjerling, S. Vaulont, P. D. Neufer, E. A. Richter and H. Pilegaard: Effects of alpha-AMPK knockout on exercise-induced gene activation in mouse skeletal muscle. Faseb J, 19 (9), 1146-8 (2005)

77. K. S. Rockl, M. F. Hirshman, J. Brandauer, N. Fujii, L. A. Witters and L. J. Goodyear: Skeletal muscle adaptation to exercise training: AMP-activated protein kinase mediates muscle fiber type shift. Diabetes, 56 (8), 2062-9 (2007)

78. M. Bluher, J. W. Bullen, Jr., J. H. Lee, S. Kralisch, M. Fasshauer, N. Kloting, J. Niebauer, M. R. Schon, C. J. Williams and C. S. Mantzoros: Circulating adiponectin and expression of adiponectin receptors in human skeletal muscle: associations with metabolic parameters and insulin resistance and regulation by physical training. $J$ Clin Endocrinol Metab, 91 (6), 2310-6 (2006)

79. K. Hojlund, K. J. Mustard, P. Staehr, D. G. Hardie, H. Beck-Nielsen, E. A. Richter and J. F. Wojtaszewski: AMPK activity and isoform protein expression are similar in muscle of obese subjects with and without type 2 diabetes. Am J Physiol Endocrinol Metab, 286 (2), E239-44 (2004)

80. N. Musi, M. F. Hirshman, J. Nygren, M. Svanfeldt, P. Bavenholm, O. Rooyackers, G. Zhou, J. M. Williamson, O. Ljunqvist, S. Efendic, D. E. Moller, A. Thorell and L. J. Goodyear: Metformin increases AMP-activated protein kinase activity in skeletal muscle of subjects with type 2 diabetes. Diabetes, 51 (7), 2074-81 (2002)

81. L. Bertrand, A. Ginion, C. Beauloye, A. D. Hebert, B. Guigas, L. Hue and J. L. Vanoverschelde: AMPK activation restores the stimulation of glucose uptake in an in vitro model of insulin-resistant cardiomyocytes via the activation of protein kinase B. Am J Physiol Heart Circ Physiol, 291 (1), H239-50 (2006)

82. E. P. Weiss, S. B. Racette, D. T. Villareal, L. Fontana, K. Steger-May, K. B. Schechtman, S. Klein and J. O. Holloszy: Improvements in glucose tolerance and insulin action induced by increasing energy expenditure or decreasing energy intake: a randomized controlled trial. $\mathrm{Am}$ J Clin Nutr, 84 (5), 1033-42 (2006)

83. D. E. Larson-Meyer, L. K. Heilbronn, L. M. Redman, B. R. Newcomer, M. I. Frisard, S. Anton, S. R. Smith, A. Alfonso and E. Ravussin: Effect of calorie restriction with or without exercise on insulin sensitivity, beta-cell function, fat cell size, and ectopic lipid in overweight subjects. Diabetes Care, 29 (6), 1337-44 (2006)

84. I. M. Jazet, G. Schaart, A. Gastaldelli, E. Ferrannini, M. K. Hesselink, P. Schrauwen, J. A. Romijn, J. A. Maassen, H. Pijl, D. M. Ouwens and A. E. Meinders: Loss of 50\% of excess weight using a very low energy diet improves insulin-stimulated glucose disposal and skeletal muscle insulin signalling in obese insulin-treated type 2 diabetic patients. Diabetologia, 51 (2), 309-19 (2008)

85. S. Hammer, M. Snel, H. J. Lamb, I. M. Jazet, R. W. van der Meer, H. Pijl, E. A. Meinders, J. A. Romijn, A. de Roos and J. W. Smit: Prolonged caloric restriction in obese patients with type 2 diabetes mellitus decreases myocardial triglyceride content and improves myocardial function. $J$ Am Coll Cardiol, 52 (12), 1006-12 (2008)

86. K. T. Howitz, K. J. Bitterman, H. Y. Cohen, D. W. Lamming, S. Lavu, J. G. Wood, R. E. Zipkin, P. Chung, A. Kisielewski, L. L. Zhang, B. Scherer and D. A. Sinclair: Small molecule activators of sirtuins extend Saccharomyces cerevisiae lifespan. Nature, 425 (6954), 191-6 (2003)

87. J. A. Baur, K. J. Pearson, N. L. Price, H. A. Jamieson, C. Lerin, A. Kalra, V. V. Prabhu, J. S. Allard, G. LopezLluch, K. Lewis, P. J. Pistell, S. Poosala, K. G. Becker, O. Boss, D. Gwinn, M. Wang, S. Ramaswamy, K. W. Fishbein, R. G. Spencer, E. G. Lakatta, D. Le Couteur, R. J. Shaw, P. Navas, P. Puigserver, D. K. Ingram, R. de Cabo and D. A. Sinclair: Resveratrol improves health and survival of mice on a high-calorie diet. Nature, 444 (7117), 337-42 (2006)

88. M. Zang, S. Xu, K. A. Maitland-Toolan, A. Zuccollo, X. Hou, B. Jiang, M. Wierzbicki, T. J. Verbeuren and R. A. Cohen: Polyphenols stimulate AMP-activated protein kinase, lower lipids, and inhibit accelerated atherosclerosis in diabetic LDL receptor-deficient mice. Diabetes, 55 (8), 2180-91 (2006)

89. M. Lagouge, C. Argmann, Z. Gerhart-Hines, H. Meziane, C. Lerin, F. Daussin, N. Messadeq, J. Milne, P. Lambert, P. Elliott, B. Geny, M. Laakso, P. Puigserver and J. Auwerx: Resveratrol improves mitochondrial function and protects against metabolic disease by activating SIRT1 and PGC-1alpha. Cell, 127 (6), 1109-22 (2006)

90. J. C. Milne, P. D. Lambert, S. Schenk, D. P. Carney, J. J. Smith, D. J. Gagne, L. Jin, O. Boss, R. B. Perni, C. B. Vu, J. E. Bemis, R. Xie, J. S. Disch, P. Y. Ng, J. J. Nunes, A. V. Lynch, H. Yang, H. Galonek, K. Israelian, W. Choy, A. Iffland, S. Lavu, O. Medvedik, D. A. Sinclair, J. M. Olefsky, M. R. Jirousek, P. J. Elliott and C. H. Westphal: Small molecule activators of SIRT1 as therapeutics for the treatment of type 2 diabetes. Nature, 450 (7170), 712-6 (2007)

91. C. Sun, F. Zhang, X. Ge, T. Yan, X. Chen, X. Shi and Q. Zhai: SIRT1 improves insulin sensitivity under insulin-resistant conditions by repressing PTP1B. Cell Metab, 6 (4), 307-19 (2007)

92. A. S. Banks, N. Kon, C. Knight, M. Matsumoto, R. Gutierrez-Juarez, L. Rossetti, W. Gu and D. Accili: SirT1 gain of function increases energy efficiency and prevents diabetes in mice. Cell Metab, 8 (4), 333-41 (2008) 
93. K. A. Moynihan, A. A. Grimm, M. M. Plueger, E. Bernal-Mizrachi, E. Ford, C. Cras-Meneur, M. A. Permutt and S. Imai: Increased dosage of mammalian Sir2 in pancreatic beta cells enhances glucose-stimulated insulin secretion in mice. Cell Metab, 2 (2), 105-17 (2005)

94. L. Bordone, M. C. Motta, F. Picard, A. Robinson, U. S. Jhala, J. Apfeld, T. McDonagh, M. Lemieux, M. McBurney, A. Szilvasi, E. J. Easlon, S. J. Lin and L. Guarente: Sirtl regulates insulin secretion by repressing UCP2 in pancreatic beta cells. PLoS Biol, 4 (2), e31 (2006)

95. F. Picard, M. Kurtev, N. Chung, A. Topark-Ngarm, T. Senawong, R. Machado De Oliveira, M. Leid, M. W. McBurney and L. Guarente: Sirtl promotes fat mobilization in white adipocytes by repressing PPARgamma. Nature, 429 (6993), 771-6 (2004)

96. J. A. Baur, K. J. Pearson, N. L. Price, H. A. Jamieson, C. Lerin, A. Kalra, V. V. Prabhu, J. S. Allard, G. LopezLluch, K. Lewis, P. J. Pistell, S. Poosala, K. G. Becker, O. Boss, D. Gwinn, M. Wang, S. Ramaswamy, K. W. Fishbein, R. G. Spencer, E. G. Lakatta, D. Le Couteur, R. J. Shaw, P. Navas, P. Puigserver, D. K. Ingram, R. de Cabo and D. A. Sinclair: Resveratrol improves health and survival of mice on a high-calorie diet. Nature, 444 (7117), 337-42 (2006)

97. Q. F. Collins, H. Y. Liu, J. Pi, Z. Liu, M. J. Quon and W. Cao: Epigallocatechin-3-gallate (EGCG), a green tea polyphenol, suppresses hepatic gluconeogenesis through 5'AMP-activated protein kinase. J Biol Chem, 282 (41), 30143-9 (2007)

98. X. Hou, S. Xu, K. A. Maitland-Toolan, K. Sato, B. Jiang, Y. Ido, F. Lan, K. Walsh, M. Wierzbicki, T. J. Verbeuren, R. A. Cohen and M. Zang: SIRT1 regulates hepatocyte lipid metabolism through activating AMPactivated protein kinase. J Biol Chem, 283 (29), 20015-26 (2008)

99. B. Dasgupta and J. Milbrandt: Resveratrol stimulates AMP kinase activity in neurons. Proc Natl Acad Sci U S A, 104 (17), 7217-22 (2007)

100. G. Zhou, R. Myers, Y. Li, Y. Chen, X. Shen, J. FenykMelody, M. Wu, J. Ventre, T. Doebber, N. Fujii, N. Musi, M. F. Hirshman, L. J. Goodyear and D. E. Moller: Role of AMP-activated protein kinase in mechanism of metformin action. J Clin Invest, 108 (8), 1167-74 (2001)

101. R. J. Shaw, K. A. Lamia, D. Vasquez, S. H. Koo, N. Bardeesy, R. A. Depinho, M. Montminy and L. C. Cantley: The kinase LKB1 mediates glucose homeostasis in liver and therapeutic effects of metformin. Science, 310 (5754), 1642-6 (2005)

102. M. Foretz, N. Ancellin, F. Andreelli, Y. Saintillan, P. Grondin, A. Kahn, B. Thorens, S. Vaulont and B. Viollet: Short-term overexpression of a constitutively active form of AMP-activated protein kinase in the liver leads to mild hypoglycemia and fatty liver. Diabetes, 54 (5), 1331-9 (2005)

103. A. Y. Viana, H. Sakoda, M. Anai, M. Fujishiro, H. Ono, A. Kushiyama, Y. Fukushima, Y. Sato, Y. Oshida, Y. Uchijima, H. Kurihara and T. Asano: Role of hepatic AMPK activation in glucose metabolism and dexamethasone-induced regulation of AMPK expression. Diabetes Res Clin Pract, 73 (2), 135-42 (2006)

104. P. A. Lochhead, I. P. Salt, K. S. Walker, D. G. Hardie and C. Sutherland: 5-aminoimidazole-4-carboxamide riboside mimics the effects of insulin on the expression of the 2 key gluconeogenic genes PEPCK and glucose-6phosphatase. Diabetes, 49 (6), 896-903 (2000)

105. S. H. Koo, L. Flechner, L. Qi, X. Zhang, R. A. Screaton, S. Jeffries, S. Hedrick, W. Xu, F. Boussouar, P. Brindle, H. Takemori and M. Montminy: The CREB coactivator TORC2 is a key regulator of fasting glucose metabolism. Nature, 437 (7062), 1109-11 (2005)

106. R. R. Banerjee, S. M. Rangwala, J. S. Shapiro, A. S. Rich, B. Rhoades, Y. Qi, J. Wang, M. W. Rajala, A. Pocai, P. E. Scherer, C. M. Steppan, R. S. Ahima, S. Obici, L. Rossetti and M. A. Lazar: Regulation of fasted blood glucose by resistin. Science, 303 (5661), 1195-8 (2004)

107. T. Yamauchi, J. Kamon, Y. Minokoshi, Y. Ito, H. Waki, S. Uchida, S. Yamashita, M. Noda, S. Kita, K. Ueki, K. Eto, Y. Akanuma, P. Froguel, F. Foufelle, P. Ferre, D. Carling, S. Kimura, R. Nagai, B. B. Kahn and T. Kadowaki: Adiponectin stimulates glucose utilization and fatty-acid oxidation by activating AMP-activated protein kinase. Nat Med, 8 (11), 1288-95 (2002)

108. F. Andreelli, M. Foretz, C. Knauf, P. D. Cani, C. Perrin, M. A. Iglesias, B. Pillot, A. Bado, F. Tronche, G. Mithieux, S. Vaulont, R. Burcelin and B. Viollet: Liver adenosine monophosphate-activated kinase-alpha2 catalytic subunit is a key target for the control of hepatic glucose production by adiponectin and leptin but not insulin. Endocrinology, 147 (5), 2432-41 (2006)

109. H. A. Koistinen, D. Galuska, A. V. Chibalin, J. Yang, J. R. Zierath, G. D. Holman and H. Wallberg-Henriksson: 5-amino-imidazole carboxamide riboside increases glucose transport and cell-surface GLUT4 content in skeletal muscle from subjects with type 2 diabetes. Diabetes, 52 (5), 1066-72 (2003)

110. K. Sakamoto and G. D. Holman: Emerging role for AS160/TBC1D4 and TBC1D1 in the regulation of GLUT4 traffic. Am J Physiol Endocrinol Metab, 295 (1), E29-37 (2008)

111. E. B. Taylor, D. An, H. F. Kramer, H. Yu, N. L. Fujii, K. S. Roeckl, N. Bowles, M. F. Hirshman, J. Xie, E. P. Feener and L. J. Goodyear: Discovery of TBC1D1 as an insulin-, AICAR-, and contraction-stimulated signaling nexus in mouse skeletal muscle. J Biol Chem, 283 (15), 9787-96 (2008) 
112. H. C. Dreyer, M. J. Drummond, E. L. Glynn, S. Fujita, D. L. Chinkes, E. Volpi and B. B. Rasmussen: Resistance exercise increases human skeletal muscle AS160/TBC1D4 phosphorylation in association with enhanced leg glucose uptake during post-exercise recovery. J Appl Physiol (2008)

113. A. Sriwijitkamol, D. K. Coletta, E. Wajcberg, G. B. Balbontin, S. M. Reyna, J. Barrientes, P. A. Eagan, C. P. Jenkinson, E. Cersosimo, R. A. DeFronzo, K. Sakamoto and N. Musi: Effect of acute exercise on AMPK signaling in skeletal muscle of subjects with type 2 diabetes: a timecourse and dose-response study. Diabetes, 56 (3), 836-48 (2007)

114. L. Storlien, N. D. Oakes and D. E. Kelley: Metabolic flexibility. Proc Nutr Soc, 63 (2), 363-8 (2004)

115. K. F. Petersen, E. A. Oral, S. Dufour, D. Befroy, C. Ariyan, C. Yu, G. W. Cline, A. M. DePaoli, S. I. Taylor, P. Gorden and G. I. Shulman: Leptin reverses insulin resistance and hepatic steatosis in patients with severe lipodystrophy. J Clin Invest, 109 (10), 1345-50 (2002)

116. S. Kamohara, R. Burcelin, J. L. Halaas, J. M. Friedman and M. J. Charron: Acute stimulation of glucose metabolism in mice by leptin treatment. Nature, 389 (6649), 374-7 (1997)

117. Y. Minokoshi, M. S. Haque and T. Shimazu: Microinjection of leptin into the ventromedial hypothalamus increases glucose uptake in peripheral tissues in rats. Diabetes, 48 (2), 287-91 (1999)

118. Y. Minokoshi, Y. B. Kim, O. D. Peroni, L. G. Fryer, C. Muller, D. Carling and B. B. Kahn: Leptin stimulates fattyacid oxidation by activating AMP-activated protein kinase. Nature, 415 (6869), 339-43 (2002)

119. C. R. Bruce, V. A. Mertz, G. J. Heigenhauser and D. J. Dyck: The stimulatory effect of globular adiponectin on insulin-stimulated glucose uptake and fatty acid oxidation is impaired in skeletal muscle from obese subjects. Diabetes, 54 (11), 3154-60 (2005)

120. M. A. Febbraio and B. K. Pedersen: Contraction-induced myokine production and release: is skeletal muscle an endocrine organ? Exerc Sport Sci Rev, 33 (3), 114-9 (2005)

121. S. Glund, A. Deshmukh, Y. C. Long, T. Moller, H. A. Koistinen, K. Caidahl, J. R. Zierath and A. Krook: Interleukin6 directly increases glucose metabolism in resting human skeletal muscle. Diabetes, 56 (6), 1630-7 (2007)

122. I. Nieto-Vazquez, S. Fernandez-Veledo, C. de Alvaro and M. Lorenzo: Dual Role of Interleukin-6 in Regulating Insulin Sensitivity in Murine Skeletal Muscle. Diabetes (2008)

123. S. Glund, J. T. Treebak, Y. C. Long, R. Barres, B. Viollet, J. F. Wojtaszewski and J. R. Zierath: Role of AMPK in IL-6 release from isolated mouse skeletal muscle. Endocrinology (2008)
124. I. Leclerc, C. Lenzner, L. Gourdon, S. Vaulont, A. Kahn and B. Viollet: Hepatocyte nuclear factor-4alpha involved in type 1 maturity-onset diabetes of the young is a novel target of AMP-activated protein kinase. Diabetes, 50 (7), 1515-21 (2001)

125. A. Woods, D. Azzout-Marniche, M. Foretz, S. C. Stein, P. Lemarchand, P. Ferre, F. Foufelle and D. Carling: Characterization of the role of AMP-activated protein kinase in the regulation of glucose-activated gene expression using constitutively active and dominant negative forms of the kinase. Mol Cell Biol, 20 (18), 6704-11 (2000)

126. M. Foretz, D. Carling, C. Guichard, P. Ferre and F. Foufelle: AMP-activated protein kinase inhibits the glucose-activated expression of fatty acid synthase gene in rat hepatocytes. J Biol Chem, 273 (24), 14767-71 (1998)

127. I. Leclerc, A. Kahn and B. Doiron: The 5'-AMPactivated protein kinase inhibits the transcriptional stimulation by glucose in liver cells, acting through the glucose response complex. FEBS Lett, 431 (2), 180-4 (1998)

128. M. M. Assifi, G. Suchankova, S. Constant, M. Prentki, A. K. Saha and N. B. Ruderman: AMP-activated protein kinase and coordination of hepatic fatty acid metabolism of starved/carbohydrate-refed rats. Am J Physiol Endocrinol Metab, 289 (5), E794-800 (2005)

129. G. F. Merrill, E. J. Kurth, D. G. Hardie and W. W. Winder: AICA riboside increases AMP-activated protein kinase, fatty acid oxidation, and glucose uptake in rat muscle. Am J Physiol, 273 (6 Pt 1), E1107-12 (1997)

130. W. J. Lee, M. Kim, H. S. Park, H. S. Kim, M. J. Jeon, K. S. Oh, E. H. Koh, J. C. Won, M. S. Kim, G. T. Oh, M. Yoon, K. U. Lee and J. Y. Park: AMPK activation increases fatty acid oxidation in skeletal muscle by activating PPARalpha and PGC-1. Biochem Biophys Res Commun, 340 (1), 291-5 (2006)

131. B. R. Barnes, S. Marklund, T. L. Steiler, M. Walter, G. Hjalm, V. Amarger, M. Mahlapuu, Y. Leng, C. Johansson, D. Galuska, K. Lindgren, M. Abrink, D. Stapleton, J. R. Zierath and L. Andersson: The 5'-AMPactivated protein kinase gamma3 isoform has a key role in carbohydrate and lipid metabolism in glycolytic skeletal muscle. J Biol Chem, 279 (37), 38441-7 (2004)

132. N. L. Dzamko, J. D. Schertzer, J. Ryall, R. Steel, S. L. Macaulay, S. Wee, Z. P. Chen, B. J. Michell, J. S. Oakhill, M. J. Watt, S. B. Jorgensen, G. S. Lynch, B. E. Kemp and G. R. Steinberg: AMPK independent pathways regulate skeletal muscle fatty acid oxidation. $J$ Physiol (2008)

133. A. C. Smith, C. R. Bruce and D. J. Dyck: AMP kinase activation with AICAR further increases fatty acid oxidation and blunts triacylglycerol hydrolysis in 
contracting rat soleus muscle. $J$ Physiol, 565 (Pt 2), 547-53 (2005)

134. J. F. Wojtaszewski, M. Mourtzakis, T. Hillig, B. Saltin and H. Pilegaard: Dissociation of AMPK activity and ACCbeta phosphorylation in human muscle during prolonged exercise. Biochem Biophys Res Commun, 298 (3), 309-16 (2002)

135. C. Roepstorff, N. Halberg, T. Hillig, A. K. Saha, N. B. Ruderman, J. F. Wojtaszewski, E. A. Richter and B. Kiens: Malonyl-CoA and carnitine in regulation of fat oxidation in human skeletal muscle during exercise. Am J Physiol Endocrinol Metab, 288 (1), E133-42 (2005)

136. H. Z. Lin, S. Q. Yang, C. Chuckaree, F. Kuhajda, G. Ronnet and A. M. Diehl: Metformin reverses fatty liver disease in obese, leptin-deficient mice. Nat Med, 6 (9), 998-1003 (2000)

137. A. Xu, Y. Wang, H. Keshaw, L. Y. Xu, K. S. Lam and G. J. Cooper: The fat-derived hormone adiponectin alleviates alcoholic and nonalcoholic fatty liver diseases in mice. J Clin Invest, 112 (1), 91-100 (2003)

138. T. Yamauchi, J. Kamon, H. Waki, Y. Terauchi, N. Kubota, K. Hara, Y. Mori, T. Ide, K. Murakami, N. Tsuboyama-Kasaoka, O. Ezaki, Y. Akanuma, O. Gavrilova, C. Vinson, M. L. Reitman, H. Kagechika, K. Shudo, M. Yoda, Y. Nakano, K. Tobe, R. Nagai, S. Kimura, M. Tomita, P. Froguel and T. Kadowaki: The fat-derived hormone adiponectin reverses insulin resistance associated with both lipoatrophy and obesity. Nat Med, 7 (8), 941-6 (2001)

139. B. Cool, B. Zinker, W. Chiou, L. Kifle, N. Cao, M. Perham, R. Dickinson, A. Adler, G. Gagne, R. Iyengar, G. Zhao, K. Marsh, P. Kym, P. Jung, H. S. Camp and E. Frevert: Identification and characterization of a small molecule AMPK activator that treats key components of type 2 diabetes and the metabolic syndrome. Cell Metab, 3 (6), 403-16 (2006)

140. J. T. Rodgers and P. Puigserver: Fasting-dependent glucose and lipid metabolic response through hepatic sirtuin 1. Proc Natl Acad Sci U S A, 104 (31), 12861-6 (2007)

141. B. Guigas, N. Taleux, M. Foretz, D. Detaille, F. Andreelli, B. Viollet and L. Hue: AMP-activated protein kinase-independent inhibition of hepatic mitochondrial oxidative phosphorylation by AICA riboside. Biochem J, 404 (3), 499-507 (2007)

142. H. Boon, M. Bosselaar, S. F. Praet, E. E. Blaak, W. H. Saris, A. J. Wagenmakers, S. L. McGee, C. J. Tack, P. Smits, M. Hargreaves and L. J. van Loon: Intravenous AICAR administration reduces hepatic glucose output and inhibits whole body lipolysis in type 2 diabetic patients. Diabetologia, 51 (10), 1893-900 (2008)

143. S. E. Kahn: The relative contributions of insulin resistance and beta-cell dysfunction to the pathophysiology of Type 2 diabetes. Diabetologia, 46 (1), 3-19 (2003)
144. U.K. prospective diabetes study 16 . Overview of 6 years' therapy of type II diabetes: a progressive disease. U.K. Prospective Diabetes Study Group. Diabetes, 44 (11), 1249-58 (1995)

145. M. Prentki, E. Joly, W. El-Assaad and R. Roduit: Malonyl-CoA signaling, lipid partitioning, and glucolipotoxicity: role in beta-cell adaptation and failure in the etiology of diabetes. Diabetes, 51 Suppl 3, S405-13 (2002)

146. W. El-Assaad, J. Buteau, M. L. Peyot, C. Nolan, R. Roduit, S. Hardy, E. Joly, G. Dbaibo, L. Rosenberg and M. Prentki: Saturated fatty acids synergize with elevated glucose to cause pancreatic beta-cell death. Endocrinology, 144 (9), 4154-63 (2003)

147. M. Higa, Y. T. Zhou, M. Ravazzola, D. Baetens, L. Orci and R. H. Unger: Troglitazone prevents mitochondrial alterations, beta cell destruction, and diabetes in obese prediabetic rats. Proc Natl Acad Sci U S A, 96 (20), 115138 (1999)

148. R. Lupi, S. Del Guerra, V. Fierabracci, L. Marselli, M. Novelli, G. Patane, U. Boggi, F. Mosca, S. Piro, S. Del Prato and P. Marchetti: Lipotoxicity in human pancreatic islets and the protective effect of metformin. Diabetes, 51 Suppl 1, S134-7 (2002)

149. K. Eto, T. Yamashita, J. Matsui, Y. Terauchi, M. Noda and T. Kadowaki: Genetic manipulations of fatty acid metabolism in beta-cells are associated with dysregulated insulin secretion. Diabetes, 51 Suppl 3, S414-20 (2002)

150. B. A. Kefas, H. Heimberg, S. Vaulont, D. Meisse, L. Hue, D. Pipeleers and M. Van de Casteele: AICA-riboside induces apoptosis of pancreatic beta cells through stimulation of AMP-activated protein kinase. Diabetologia, 46 (2), 250-4 (2003)

151. B. A. Kefas, Y. Cai, Z. Ling, H. Heimberg, L. Hue, D. Pipeleers and M. Van de Casteele: AMP-activated protein kinase can induce apoptosis of insulin-producing MIN6 cells through stimulation of c-Jun-N-terminal kinase. J Mol Endocrinol, 30 (2), 151-61 (2003)

152. A. Riboulet-Chavey, F. Diraison, L. K. Siew, F. S. Wong and G. A. Rutter: Inhibition of AMP-activated protein kinase protects pancreatic beta-cells from cytokinemediated apoptosis and CD8+ T-cell-induced cytotoxicity. Diabetes, 57 (2), 415-23 (2008)

153. W. H. Kim, J. W. Lee, Y. H. Suh, H. J. Lee, S. H. Lee, Y. K. Oh, B. Gao and M. H. Jung: AICAR potentiates ROS production induced by chronic high glucose: roles of AMPK in pancreatic beta-cell apoptosis. Cell Signal, 19 (4), 791-805 (2007)

154. P. Marchetti, S. Del Guerra, L. Marselli, R. Lupi, M. Masini, M. Pollera, M. Bugliani, U. Boggi, F. Vistoli, F. Mosca and S. Del Prato: Pancreatic islets from type 2 diabetic patients have functional defects and increased 
apoptosis that are ameliorated by metformin. $J$ Clin Endocrinol Metab, 89 (11), 5535-41 (2004)

155. S. K. Richards, L. E. Parton, I. Leclerc, G. A. Rutter and R. M. Smith: Over-expression of AMP-activated protein kinase impairs pancreatic \{beta\}-cell function in vivo. J Endocrinol, 187 (2), 225-35 (2005)

156. I. Leclerc, W. W. Woltersdorf, G. da Silva Xavier, R. L. Rowe, S. E. Cross, G. S. Korbutt, R. V. Rajotte, R. Smith and G. A. Rutter: Metformin, but not leptin, regulates AMP-activated protein kinase in pancreatic islets: impact on glucose-stimulated insulin secretion. $\mathrm{Am} \mathrm{J}$ Physiol Endocrinol Metab, 286 (6), E1023-31 (2004)

157. G. da Silva Xavier, I. Leclerc, A. Varadi, T. Tsuboi, S. K. Moule and G. A. Rutter: Role for AMP-activated protein kinase in glucose-stimulated insulin secretion and preproinsulin gene expression. Biochem J, 371 (Pt 3), 761$74(2003)$

158. I. P. Salt, G. Johnson, S. J. Ashcroft and D. G. Hardie: AMP-activated protein kinase is activated by low glucose in cell lines derived from pancreatic beta cells, and may regulate insulin release. Biochem J, 335 ( Pt 3), 533-9 (1998)

159. X. Wang, L. Zhou, L. Shao, L. Qian, X. Fu, G. Li, T. Luo, Y. Gu, F. Li, J. Li, S. Zheng and M. Luo: Troglitazone acutely activates AMP-activated protein kinase and inhibits insulin secretion from beta cells. Life Sci, 81 (2), 160-5 (2007)

160. L. Zhou, X. Wang, L. Shao, Y. Yang, W. Shang, G. Yuan, B. Jiang, F. Li, J. Tang, H. Jing and M. Chen: Berberine acutely inhibits insulin secretion from beta-cells through 3',5'-cyclic adenosine 5'-monophosphate signaling pathway. Endocrinology, 149 (9), 4510-8 (2008)

161. T. Tsuboi, G. da Silva Xavier, I. Leclerc and G. A. Rutter: 5'-AMP-activated protein kinase controls insulincontaining secretory vesicle dynamics. J Biol Chem, 278 (52), 52042-51 (2003)

162. R. D. Carr, C. L. Brand, T. B. Bodvarsdottir, J. B. Hansen and J. Sturis: NN414, a SUR1/Kir6.2-selective potassium channel opener, reduces blood glucose and improves glucose tolerance in the VDF Zucker rat. Diabetes, 52 (10), 2513-8 (2003)

163. A. E. Butler, J. Janson, S. Bonner-Weir, R. Ritzel, R. A. Rizza and P. C. Butler: Beta-cell deficit and increased beta-cell apoptosis in humans with type 2 diabetes. Diabetes, 52 (1), 102-10 (2003)

164. A. Pick, J. Clark, C. Kubstrup, M. Levisetti, W. Pugh, S. Bonner-Weir and K. S. Polonsky: Role of apoptosis in failure of beta-cell mass compensation for insulin resistance and beta-cell defects in the male Zucker diabetic fatty rat. Diabetes, 47 (3), 358-64 (1998)

165. C. E. Murry, R. B. Jennings and K. A. Reimer: Preconditioning with ischemia: a delay of lethal cell injury in ischemic myocardium. Circulation, 74 (5), 1124-36 (1986)

166. Y. Nishino, T. Miura, T. Miki, J. Sakamoto, Y. Nakamura, Y. Ikeda, H. Kobayashi and K. Shimamoto: Ischemic preconditioning activates AMPK in a PKCdependent manner and induces GLUT4 up-regulation in the late phase of cardioprotection. Cardiovascular research, 61 (3), 610-9 (2004)

167. R. Shibata, K. Sato, D. R. Pimentel, Y. Takemura, S. Kihara, K. Ohashi, T. Funahashi, N. Ouchi and K. Walsh: Adiponectin protects against myocardial ischemiareperfusion injury through AMPK- and COX-2-dependent mechanisms. Nat Med, 11 (10), 1096-103 (2005)

168. R. Shibata, N. Ouchi, M. Ito, S. Kihara, I. Shiojima, D. R. Pimentel, M. Kumada, K. Sato, S. Schiekofer, K. Ohashi, T. Funahashi, W. S. Colucci and K. Walsh: Adiponectin-mediated modulation of hypertrophic signals in the heart. Nat Med, 10 (12), 1384-9 (2004)

169. D. Fujioka, K. Kawabata, Y. Saito, T. Kobayashi, T. Nakamura, Y. Kodama, H. Takano, J. E. Obata, Y. Kitta, K. Umetani and K. Kugiyama: Role of adiponectin receptors in endothelin-induced cellular hypertrophy in cultured cardiomyocytes and their expression in infarcted heart. Am J Physiol Heart Circ Physiol, 290 (6), H2409-16 (2006)

170. J. B. Majithiya and R. Balaraman: Metformin reduces blood pressure and restores endothelial function in aorta of streptozotocin-induced diabetic rats. Life Sci, 78 (22), 2615-24 (2006)

171. L. J. Rubin, L. Magliola, X. Feng, A. W. Jones and C. C. Hale: Metabolic activation of AMP kinase in vascular smooth muscle. J Appl Physiol, 98 (1), 296-306 (2005)

172. A. M. Evans, K. J. Mustard, C. N. Wyatt, C. Peers, M. Dipp, P. Kumar, N. P. Kinnear and D. G. Hardie: Does AMP-activated protein kinase couple inhibition of mitochondrial oxidative phosphorylation by hypoxia to calcium signaling in O2-sensing cells? J Biol Chem, 280 (50), 41504-11 (2005)

173. R. Shibata, N. Ouchi, S. Kihara, K. Sato, T. Funahashi and K. Walsh: Adiponectin stimulates angiogenesis in response to tissue ischemia through stimulation of ampactivated protein kinase signaling. J Biol Chem, 279 (27), 28670-4 (2004)

174. Y. Minokoshi, T. Alquier, N. Furukawa, Y. B. Kim, A. Lee, B. Xue, J. Mu, F. Foufelle, P. Ferre, M. J. Birnbaum, B. J. Stuck and B. B. Kahn: AMP-kinase regulates food intake by responding to hormonal and nutrient signals in the hypothalamus. Nature, 428 (6982), 569-74 (2004)

175. B. Cool, B. Zinker, W. Chiou, L. Kifle, N. Cao, M. Perham, R. Dickinson, A. Adler, G. Gagne, R. Iyengar, G. Zhao, K. Marsh, P. Kym, P. Jung, H. S. Camp and E. 
Targeting AMPK in type 2 diabetes

Frevert: Identification and characterization of a small molecule AMPK activator that treats key components of type 2 diabetes and the metabolic syndrome. Cell metabolism, 3 (6), 403-16 (2006)

176. D. J. Cuthbertson, J. A. Babraj, K. J. Mustard, M. C. Towler, K. A. Green, H. Wackerhage, G. P. Leese, K. Baar, M. Thomason-Hughes, C. Sutherland, D. G. Hardie and M. J. Rennie: 5-aminoimidazole-4-carboxamide 1-beta-Dribofuranoside acutely stimulates skeletal muscle 2deoxyglucose uptake in healthy men. Diabetes, 56 (8), 2078-84 (2007)

Abbreviations: ACC: acetyl CoA carboxylase; AICAR: 5aminoimidazole-4-carboxamide riboside; AMPK: AMPactivated protein kinase; HGP: hepatic glucose production; HMG-CoA: hydroxy-3-methylglutaryl-CoA; KO, knockout; PGC-1 $\alpha$ : peroxisome proliferator-activated receptor- $\gamma$ coactivator- $1 \alpha$

Key Words: AMPK, Type 2 diabetes, Energy Metabolism, Review

Send correspondence to: Benoit Viollet, Institut Cochin, Dept of Endocrinology, Metabolism and Cancer 24 rue du Faubourg Saint-Jacques 75014 Paris, France, Tel: 33144412401 , Fax 33144412421, E-mail: benoit.viollet@inserm.fr

http://www.bioscience.org/current/vol14.htm 